\title{
The Disappearing Body: Dissection to the Extremities
}

\section{INTRODUCTION}

In eighteenth-century England no matter where the punishment of the criminal corpse took place, the essential humanity of the condemned was about to be eroded. In a strong oral culture it has however been historically difficult to substantiate with documentary evidence what it was like for the crowd assembled, containing medical men, the middling sort and labouring poor, to together be confronted with physical despoliation. This sixth chapter takes a new approach to this historical problem. Staging the punitive rites shaped the archaeology of emotions of those present. These were triggered by a 'natural curiosity' that everyone was capable of experiencing, even though many crime histories omit it. The presence of ordinary people in such large numbers indicates intention by the majority to act in some personal capacity, and to repeatedly do so, as so often featured in contemporary newspapers of the period. This found expression in a public performance of a narrative of belief, emotion, participation, exclusion and of sentiments, attached to an ever-present synaesthesia. The act of being there and expressing curiosity about the criminal corpse being opened up to public scrutiny can consequently be read as a story in itself. This fresh approach is necessary if historians are to relocate amongst the crowd the experiential history of punishment rites, in the way that anthropologists and ethnographers have done in death studies. This chapter thus investigates the cultural stimulus of 'natural curiosity' since it

(C) The Author(s) 2016

E.T. Hurren, Dissecting the Criminal Corpse, Palgrave

Historical Studies in the Criminal Corpse and its Afterlife,

DOI 10.1057/978-1-137-58249-2_6 
provides a completely different sense of how ordinary people experienced the drama of anatomy and its spectacular denouement.

Anticipating that there would be sustained interest in criminal dissections, the Universal Magazine in August 1770 soon declared:

\author{
On the Dissection of a Body \\ Observe this wonderful machine \\ View its connection with each part, \\ Thus furnish'd by the hand unseen \\ How far surpassing human art!... \\ See how the motion of each part, \\ Upon some other still depends \\ When all the material aid impart \\ Conducing to their various ends... \\ These tubes convey'd the purple juice \\ Which with new strength suppl'd the whole; \\ And here branch'd forth the nerves, whose use \\ Was to keep converse the Soul. ${ }^{1}$
}

Yet, many anatomists acknowledged that being present could also 'harrow up the feelings'. ${ }^{2}$ In material terms the criminal corpse became a 'disappearing, dirty body' by the time it was being cut 'on the extremities and to the extremities'. People naturally reacted in different ways when entering the dissection space. Some stood abreast in a tight crowded room which had the advantage that if anyone fainted they would not fall down. Many others walked in slow procession past the criminal body enabling them to say they had participated. At any time they retained the option of exiting if the spectacle was too disturbing to sensibilities. They could recoil and then come back for a second look having acclimatised to the awful sight on display. Even privileged audience members kept changing seats, staying for the removal of the heart but reserving the right to leave before the skull craniotomy. Everyone faced an anatomical storyline with an emotional sub-text of some sort; the legal aim being to make it impossible to be impassive to verify standards of justice. Here was a novel opportunity to experience new ways of seeing and believing in medicine, religion and science. This chapter is hence all about the dramatic re-enactment of the contemporary notion of post-mortem 'harm' in the popular imagination of Georgian England. 
Early modern histories have yet to convey the repopulation of peoplecoming and going-looking and standing over-handling and letting go - exiting and returning - part of a human wave of eyewitnesses at criminal dissections. Many of those that turned up suspected the corpse was on the boundaries of life/death. It was still possible to 'harm' the criminal at this stage of the punishment process and this painful subtext ignited 'natural curiosity'. The overall aim in Chapter 6 is therefore to envisage criminal dissections as a form of immersive theatre. Audiences got closer to the action because there was something for everyone involved. The criminal body should have lost its embodied identity as it became a human being despoiled, but whether it ever did when a material afterlife was created was an emotive issue, and remains so in museum culture. Section 1 thus begins by looking at what happened once the criminal corpse was cut deeply and specifically what it meant to 'harrow up the feelings' when watching the actual dissection taking place. We will see that as the external and internal appearance of the criminal changed shape, it became less than human to the lay-public. Section 2 then asks what it was about the brain and nervous system that enthralled many of those present and how exactly did those speculations start to change punishment rites. One outcome was a medical desire to dismiss the crowd before deep dissection got underway. Yet this was complicated by the agency of ordinary people too. Many however feared contagion by the criminal corpse. There was always the push and pull of public/private consumption being played out at dissection venues. Section 3 expands on this theme by exploring what it was like for medical students to engage with dissection and what a newly qualified doctor did with that experience to get on the career ladder. The aim is to rediscover some of the opportunity costs of doing criminal dissections and if ambitious surgeons relocated to areas where executed bodies were more plentiful. Finally, Section 4 engages with material afterlives and the ways that the embodied identities of criminal corpses were changing in a museum culture by 1832 .

\section{The Disappearing, Dirty Body: 'To Harrow UP THE FEELINGS'}

At an eighteenth-century criminal dissection over two-thirds of the human material was generally disposed of during the punishment rites. Today (it is worth reiterating that) in modern dissection rooms no more than 
one third of a body is used for anatomical teaching. ${ }^{3}$ That limit preserves human dignity. To dissect over two thirds in the past meant there was very little left to bury at the end. ${ }^{4}$ Most of the human waste was collected in buckets. It was then either washed away with disinfectant chemicals or put out with the rubbish because of the dangers of contagion. In a typical punishment scenario, body parts survived a lot longer than a whole body shell. Thus William Hey senior a leading Leeds surgeon in an enlightening letter on this subject wrote to Walter Spencer Stanhope on 21 March 1785. He explained why 'the extremities' were so valuable: 'as the subjects generally die in health, the bodies are sound, and the parts distinct'. ${ }^{5}$ There was however no guarantee that the body on delivery would be unblemished. It was well-known that many convicted prisoners facing the death sentence tried to commit suicide in gaol. In a representative case on 31 August 1822 at the Surrey Assizes the condemned: 'had made a most desperate effort to deprive him-self of life by inflicting several dangerous wounds upon him-self while in prison'. ${ }^{6}$ A newspaper report explained that in the case of ' $D$. Thomas sent for execution...After hanging the usual time, his body was cut down and taken to St Guy's Hospital' in central London 'for dissection in pursuance of the death sentence'. Yet, on arrival his was a 'badly damaged' corpse. The parts were worth more than the whole to the dissector on duty. There had to be a great deal of discretionary justice in the hands of the penal surgeon for this practical reason. Perhaps then it is not surprising to discover deep ambivalence in some cases about the appropriate level of post-mortem 'harm' enacted. Dissectors had to consider the nature of the capital offence, the class of the murderer, and public sensitivities. They were also under a lot of pressure to put on a good performance once criminal dissections transferred to newly built hospital infirmaries from 1810 because hospital boards were not always convinced that post-mortem punishment should be permitted on the premises.

The previous chapter explained how around the turn of the nineteenthcentury provincial dissection rooms moved location. Most were repositioned inside a courtyard or underground of local hospital infirmaries. This architectural realignment coincided with humanitarian debates about the need for executions to be carried out behind a walled-off area. At Leicester Infirmary by way of example the governing body together decided to allocate 'three rooms in the cellar' where the dissection room had a 'vaulted roof'. 7 They decreed that there should be an ante-room to prepare the body, leading to a space to dissect measuring ' 15 foot by 12 foot'. There was 'a window, overlooking the...f frontal court area' 
just above ground level to let in enough light to work but keep prying eyes out. New equipment was also ordered. 'Mr Carley' the carpenter was commissioned to 'make a Dead board for the corpses' to a bespoke design to better facilitate brain research for the penal surgeon's private use. Yet these vigilant arrangements still caused two practical problems. Keeping the general public outside could provoke the excluded mob. Indeed the Leicester Infirmary minutes of 1816 reveal how on execution days that it was 'absolutely necessary [ $\mathrm{sic}$ ] to have a strong guard for the protection of the garden and walls...for the prevention of mischief and depredation'. ${ }^{8}$ An added difficulty was that the internal move now placed criminal bodies beside an inadequate drainage system which was easily contaminated by blood, tissue and material human waste (a recurring problem in Chapters 4 and 5 at Surgeon's Hall from 1752). Just because original research was being pioneered on the criminal corpse did not mean that dissectors could avoid the logistics of contagion. Not only was this was one the biggest public health nuisances that all provincial anatomists faced after the Murder Act, but ironically it proved to be such a difficult problem to resolve that it led to better professional recognition that dissection should be the preserve of the medical fraternity. ${ }^{9}$ Conditions in the Midlands are enlightening and reveal the strong connection there was between practical considerations and the emotions they often stimulated.

Derby Infirmary was proud of its new brain research on criminal corpses but preventing contagion from decomposing bodies was testing. If the local medical fraternity wanted to enhance their reputations for doing original research, it was important that they publicize what steps they were taking to sort out basic health and safety issues. Nobody was going to be convinced by research on criminal corpses that ironically kept killing penal surgeons! Erasmus Darwin throughout his career took a keen interest in these practical problems for personal and professional reasons. ${ }^{10}$ His young cousin Charles Darwin aged just 20 when a medical student caught a fatal infection after 'dissecting the brain of child which had died of hydrocephalus' at Edinburgh' in 1778. ${ }^{11}$ A careless nick of the lancet was a well-known hazard, causing cross-contamination in the anatomist's hands. Thus when Thomas Alcock RCS, and a leading light in the Medical and Chirurgical Society published his much-praised, An Essay on the Use of Chlorurets of Oxide of Sodium and of Lime as Powerful Disinfecting Agents and so on (1827), he highlighted best practice established in dissection rooms in places like the Derbyshire General Infirmary. He advised: 
The covering of tables with lead, or any substance incapable of absorbing moisture is advantageous, whilst a simple contrivance, a conducting pipe, for conveying any liquids from the table to the bucket underneath, prevents them from flowing upon the floor. Each table or pair of tables should have a water pipe with a stopcock and a moveable spout, and a constant supply of water, to be used when occasion may require... The material of which the floor is composed, should be incapable of absorbing water - stone or stucco answers this purpose... The most strict attention to cleanliness, and to the removal of useless parts, should be carried into effect. ${ }^{12}$

This room design, basic equipment, and procedures for carefully disposing of body-parts after dissection, were evidently not in place when Shire Halls and small medical dispensaries had been requisitioned for the postmortem punishment of criminal corpses from the 1750s to the $1810 \mathrm{~s}$. The transfer of the condemned body by Judge's warrant to purpose-built infirmaries around 1815 thus heralded a noticeably more 'professional' style of dissection work. Alcock's health and safety reforms also reveal important details about the odour of the room and the way the body looked once the dissectors got to work. He advised: 'The floor should be washed with chlorureted water' [chloride] to disinfect it but this also gave the room a pungent smell of cat urine, a necessary but offensive odour. To prevent putrefaction of the corpse Alcock suggested applying a 'solution of chloruret of lime or of soda over the subject each time before beginning to dissect, removing with a sponge all superfluous moisture'. ${ }^{13} \mathrm{He}$ reminded his medical audience and general readers that body fluids did go on leaking even two or three days after medical death and that dissectors needed to re-sprinkle the corpse with chloruret each day which although malodorous was better than a fouler stench emanating from a decomposing corpse. It was also best he observed to cover the 'subject with a coarse cloth or cloths moistened' in the 'solution of chloruret ... cloths should be renewed night and morning'.

There were then a number of techniques that could be used to preserve the criminal body to extend its use as a teaching aid and it was these that tended to have an emotional impact once dissection became a preservation race against putrefaction. Of these, Alcock claimed to have perfected injecting 'a saturated solution of pure muriate of soda with a little nitre [saltpeter]...into the arteries without heat: this will considerably retard putrefaction; but does not preserve the florid appearance of the muscles'. ${ }^{14}$ If the dissector needed to 'distend the blood vessels' in the case of major arterial vessels he injected 'red lead' so students could see this run through 
the corpse. If working on minute vessels it was better to do a 'fine injection consisting of spirit varnish and vermillion'. White lead for example mixed with oil on vermillion and thinned to the right consistency with turpentine worked well-it ought to be the 'consistency of treacle and should be gently injected to the arteries'. In the case of the veins it was advisable to use a different colour, 'either rose-pink or a powder-blue' paint base. Many medical men nonetheless still preferred working in wax because it preserved parts for longer. Whatever the chosen preservation method, the visual effect was that the actual corpse changed its physical appearance at an alarming rate in front of the crowd. The greatest challenge Alcock pointed out was working in warmer conditions when 'care must be taken to prevent the contact of flies, lest a breed of maggots should result from negligence'. If this happened chloruret sponged onto the 'mucus or slime that formed on the exposed parts' must be done. The dissector he emphasised must not touch the corpse or risk his own death from cross-contamination. The crowd could not avoid seeing bacteria eat the human flesh: a medical epitaph that was eye-catching to all sensibilities in the room, revealing how exactly 'an untimely or dramatic death began to create, as well as test, the new kind of fame' that notorious murderers started to generate in the English press and print culture of the period. ${ }^{15}$

Alcock elaborated on how best to handle a situation in which ordinary people in the crowd turned up out of 'natural curiosity' to the view of the corpse and did not anticipate just how emotional they might feel about the deceased being dissected. It was necessary under these circumstances to show 'proper attention' to how the body might be perceived by a lay audience. It was unacceptable he remarked and could 'harrow up the feelings' if a body part being examined had been 'strewed upon the table' or treated with 'the carelessness of juniors'. ${ }^{16}$ There was no doubt that if the body was not dissected quickly and it thus was 'far advanced in putrefaction' when examined that the 'clothes worn by the operators and assistants' would be 'rendered useless by the intolerable odour' that was retained. Even after being removed and laundered dissecting clothes never lost their foul smell. There was also the well-known problem of what he called 'the unsightliness of the body after examination'. In other words, once dissection was underway the process became distasteful even to those that should have been inured to the defacement of the criminal corpse. ${ }^{17}$ The most 'disgusting occupation' of all, in his professional opinion, was when 'making anatomical preparations, particularly of the bones'. It was a standard procedure 'to employ maceration till the soft parts become 
putrid and decomposed'. This involved 'the removing of the soft parts and the cleaning of the bones is ... not unfrequently attended by danger'. The advantage of using a chloruret solution in the macerating vessel was that it dampened down the smell of decomposition, cleaned the bones, and so whitened them, before the bonesetter wired them back up to make a skeleton for display.

What all of these unpalatable details suggest is that historians can retrieve an experiential sense of criminal dissections. The archive evidence again reveals that over time it remained offensive to look at, repugnant to smell; there was an eerie soundscape of dripping blood and chemical fluids flowing down temporary water-pipes into buckets. The corpse felt slimy to handle and nauseating to rub between the fingers once it started decomposing. Hair and nails had to be shaved and cut into piles left on the stonefloor for sweeping away. The flesh treated with chemicals to disinfect it smelt of cat urine from the chloride used to slow down putrefaction; above all, everyone present breathed in a lot of stagnant smells. Standard historical accounts tend to neglect this synaesthesia and produce instead a rather sterile view. Medical men did seek better professional recognition by securing a private and privileged access to criminal dissections. Yet, the balance of evidence also reveals that there was another side to this medical history too. The majority in the crowd were keen to attend the anatomization but most wanted to depart once dissection went deeper. This was understandable for reasons of personal safety and natural sensibilities. Many commentators remarked that it took a cast-iron stomach to see post-mortem 'harm' taken to its logical conclusion. Even the audience's clothes had to be discarded if someone spent too long in close proximity to the body. Hands had to be scrubbed twice a day to get rid of the lingering 'putrid effluvia'. Ordinary people heeded the medical pamphlets and publicity generated by experienced dissectors such as Thomas Alcock. General discussion provided timely warnings that 'ill-health is too frequently the consequences of close application in the dissecting rooms'. ${ }^{18}$ In an era when major epidemics like typhus fever or cholera contagion from dead bodies was a genuinely frightening prospect, few sensible people wanted to risk catching a fatal condition to satisfy their idle curiosity by lingering over a socially-diseased corpse about to be opened up to medical enquiry. Medicine therefore did dominate the criminal corpse and had the discretionary justice to do so. Yet that authority was also very much derived from an agency in the crowd, their consensus, based on popular curiosity and revulsion, about what really happened to the corpse dissected to its extremities. 
Essentially dangerous criminals in death created a dangerous duty. It was monotonous and mundane, harrowing and hazardous. This was part of the emotional conundrum of seeing social justice done. The biggest medico-legal challenge was how to get the timing right of the crowd's orderly departure. If it was not voluntary then chaos could ensure: several archival cases illustrate the public order logistics.

Two Scottish brothers Alexander (aged 35) and Michael Keands (aged 24) attacked a publican's wife Mrs Blears and murdered her servant Betty Bates at Winton near Worsley in Lancashire in 1826. Even after the guilty verdict was pronounced on 17 August at the Lancaster Assizes, neither man would admit to fatally cutting the victim's throat. The presiding Judge therefore ordered the full punishment rites according to the Murder Act. At Lancaster Castle a 'temporary scaffold covered with black cloth was erected... and two chains were attached to the fatal tree and placed very near each other'. ${ }^{19}$ If neither sibling would confess then each would be made to look into the eyes of the other in the hope that one would cry out his innocence and one his guilt at the fatal time. Alexander was the tougher of the two brothers and so the executioner made sure that 'his arms closely [were] pinioned, and the halter about his neck'. He was an audacious character and underneath the scaffold he 'turned his face towards the wall' looking away from the assembled crowd. The executioner pulled a black cap over his head and then did the same for Michael whose countenance was said to have altered as he neared death. This was taken as a sign of guilt for the murder of the servant. At the appointed time, a local reporter noted that Alexander did an odd thing. He 'took Michael's right hand in his left'. As the rope tightened, Alexander 'stopped jerking' within minutes whereas Michael 'struggled violently': emphasising some thought the latter's culpability. There was a lot of excitement in the town about whether the post-mortem punishment rites would reveal the true nature of their sinister characters.

Local accounts stress that 'several applications from individual surgeons were made to the sheriff for the bodies, but he declined granting any of them'. He had already allocated one body to Manchester infirmary-that of Michael—and, the other-of Alexander — was given to Lancaster surgeons. In the case of Alexander, a new hospital infirmary had now been built in Lancaster during 1823. This was where his criminal corpse was taken to (instead of the local medical dispensary at the bottom of Castle Hill, as we saw in the last chapter). Newspaper reporters noted that the chosen medical men had acquired the legal right under judge's warrant 
to receive the body and do the anatomization and dissection in private. However, in attempting to do so, they badly misjudged the mood of the post-execution crowd:

The body of Alexander was delivered to the infirmary on Wednesday evening and on Thursday morning, the surgeons commenced dissecting it. So great was the public curiosity to see the body, that a great crowd of persons forced their way into the dissection room, and filled it to such a degree as to put a complete stop to the operation [of the law]. The body was then taken into the yard, and exposed, and for some time, to the view [of the major organs] of all who chose to go and look at it. The dissection was resumed and, we believe, completed yesterday. ${ }^{20}$

The Lancaster medical men had neglected to include the post-execution crowd in the initial anatomization process because for such notorious men medical death had been checked three ways before reaching the dissection venue. Firstly the penal surgeon and the sheriff had done so at the scaffold, the bodies having been hanged for longer than usual (approximately an hour and a half) to make sure they were killed in front of the crowd. Secondly, each body was laid out side-by-side inside the Castle prison and the sheriff arranged for the designated Lancaster surgeons to send their assistants to collect the body from Mr Thomas Higgins keeper of the Castle. ${ }^{21}$ Before release, Higgins double-checked that Alexander and Michael were deceased by monitoring their breathing and pulse. Thirdly, both bodies were left at the Manchester and Lancaster infirmaries respectively for twenty-four hours before dissection was due to commence to check that decomposition and putrefaction had started; another fail-safe indication of medical death. In Lancaster these careful procedures however excluded the crowd, and so they bombarded the dissection room door pushing it open to view the body. In so doing, their collective actions give important new historical insights into the processes of emotional engagement in the crowd which William Reddy has called 'emotives'. ${ }^{22}$ Rather than simply 'speaking' themselves into an emotional state, changing the nature of a capital punishment experience through the self-realisation of deep-felt emotions being voiced, it is possible to argue in this context that the crowd members were equally capable of seeing, smelling, and feeling themselves into a deeper emotional awareness too. The historical cliché, 'actions speak louder than words', salient on this occasion, was a physical demonstration of the archaeology of emotions people who pushed and pulled were capable of, which in turn powerfully expressed 
the level of sustained sensations being generated at controversial criminal dissections. As a reporter for the journal The Age noted in the Sunday 26 August 1826 special edition, 'it would appear that the townships' around Lancaster 'had sent forth their entire population' to the execution and it was these 'groupes [sic] of people hurrying' to accompany the body that presented a new public order challenge for the dissectors. ${ }^{23}$ It was though remarked on in local newspapers that those present whose emotions had been aroused did not seek to touch or interfere with the criminal corpse. The crowd wanted access to the body to make sure it had paid its legal dues on the gallows, but remained disinterested in actually handling dissection per se: an important distinction. A second archival case reveals that these acts of human curiosity that triggered strong emotional and physical pressure on the part of the post-execution crowd appear to have been rooted in a collective narrative of belief, emotion, participation, exclusion and of sentiments that merit closer historical scrutiny.

James Brodie was a blind man executed for murder on the 15 July 1779. He was aged 23 and had murdered an eight year old boy. The homicide victim was a poor lad, paid a few pennies to be Brodie's guide. He was beaten to death with a stick on a turnpike road from Mansfield to Farnsfield. Brodie was evidently an angry and frustrated man. He despised his plight and took it out on a defenceless child. Brodie then tried to conceal the boy's body by burying it in a shallow grave, but it was discovered by the lad's distraught mother who came looking for him when he went missing. Brodie's violent temper was revealed in court. He started biting and kicking the constables as the judge sentenced him to death. Yet what happened next arrested the local authorities because the crowd acted with emotional intensity linked to 'the perils of curiosity'. The incidents that followed at the criminal dissection at the Shire Hall, though extreme, did expose the range of shared emotions the mob was capable of, sometimes to the shock of 'polite' society in the Midlands. It was thus reported that James Brodie was in Nottingham

submitted to the surgeons for dissection and was afterwards exposed at the County [Shire] Hall. Crowds of men, women and children, indulged their morbid curiosity by thronging the scene of this most repulsive spectacle. The mutilated and frightfully excoriated corpse lay extended on a long table with no other covering other than a loose drape thrown over the loins. Words can scarcely give an idea of the coarse and brutal jests, the obscene remarks, and the horrid and blasphemous oaths to which the display gave voice...In the height of the exhibition, when amongst the crowd were a 
number of women, a disgruntled fellow treated the body in a manner which most completely violated every feeling of decency and which his conduct excited the disapprobation of a few, and the screams and exclamations of the females, but to the great majority it served to elicit great peals of laughter. Brodie was a native of Dublin and lost his sight by an attack of the smallpox in his infancy. ${ }^{24}$

Issues of representativeness and an emotive language in this newspaper account need to be investigated carefully to assess these contemporary sentiments objectively. Nonetheless from the standpoint of the medico-legal fraternity what took place was unedifying. The crowd's reaction was very emotional, baying for revenge. Females were present but repelled; others seemed determined to express their anger by laughing over the body and seeing it exposed. Feelings of anger and revulsion were expressed in foul language. One man allegedly grabbed a body-part in a sexual way. The implicit suggestion is that he may have held the erect penis in an illicit gesture (executed males often had an erection on the rope). That the murderer was a blind man, marked by smallpox scars on his face from birth, may have made him look ugly, and this could have lessened his humanity for the crowd. Yet the newspaper reporter present attributed the level of public anger to his notoriety as a convicted child-killer. Intriguingly no mention was made of his disease or disability or ethnicity igniting public anger. There was also a striking silence on the part of the surgeons. They did not step in or call for extra support from the sheriff to try to control the public order threat. According to first-hand reports, a chorus of baying seems to have continued throughout the post-mortem 'harm'. This later justified the corpse being 'excoriated' by dissection. The authorities evidently judged that it was better to let people vent their collective anger and utilise that approbation to 'harm' the condemned flesh. If Brodie's execution had been a dramatic tragedy, this was surely its calamitous encore.

An emotional feature of these and many other cases like them relocated in the archives is the early modern concept of 'curiosity'. As Neil Kenny explains about eighteenth-century popular mentalities:

The point of invoking curiosity was almost always to regulate knowledge or behaviour, to establish who should try to want to know what, and under what circumstances. Talking or writing about curiosity was very often a way of trying to stop some people from wanting to know or do something and a way of trying to allow - or even to force - other people to know or do it. Discourse about curiosity, while not confined to questions of knowledge, played a crucial role in the production, acquisition, control and circulation of knowledge. ${ }^{25}$ 
It could moreover act as a 'salutatory warning' about the dangers of some types of curiosity-as seems to be the cases above. The postexecution crowd was criticised in contemporary newspapers for having strong emotions trigged by 'public curiosity' and/or 'morbid curiosity'. It was accepted that some type of 'natural curiosity' was necessary because its purpose was 'to legitimatize the Scientific Revolution' in which the 'new anatomy' of the 1790s was to figure so prominently during the Enlightenment. This meant though that those living in early modern society were adopting and adapting to a medico-legal discourse that 'talked about curiosity for conflicting reasons'. These aspects of dissecting the criminal corpse have been lost to posterity because of the historical predicament of oral cultures, setting in context why they are still missing in crime studies. The emotional capacity and character of the crowd in the punishment drama remains misunderstood, unless (as this chapter argues) historians accept that acts do reveal intentions and their underlying curiosities are a storyline to be read as evidence too. As Kenny points out: 'To talk or write about curiosity was usually to enter an arena'-in this case the dissection venue-'within which some of the period's basic anxieties and aspirations about knowledge and behaviour were thrashed out'. ${ }^{26}$ In early modern England curiosity came to be seen as 'usually a passion, desire, vice, or virtue in human subjects'. Postexecution crowds had curiosity because they wanted access to a body of knowledge, but this human impulse also depended on the powerful attraction of the focus of their curiosity. In terms then of controlling access and emotional reactions to the criminal corpse, there was by the $1790 \mathrm{~s}$ a fundamental shift in the cultural meaning of the sort of 'curiosity' attached to post-mortem 'harm'. It was considered to be a vice (generally in spiritual terms if questioning the theology of the afterlife of the soul) and yet a healthy passion (usually from a secular, scientific perspective about the need to engage with the anatomical punishment of the body). To have 'natural curiosity' tended to be regarded as simultaneously 'either defective, or morally neutral, or admirable' and this made it 'immensely controversial'. ${ }^{27}$ Under these circumstances it is not difficult to comprehend why it was that criminal dissections became 'even more of a battleground to distinguish good knowledge or behaviour, from bad'. Emotional impulses associated with different types of curiosity at criminal dissections can thus be illustrated in a paradigm covering eighteenth-century England, thereby providing a revisionist perspective (Figure 6.1). 


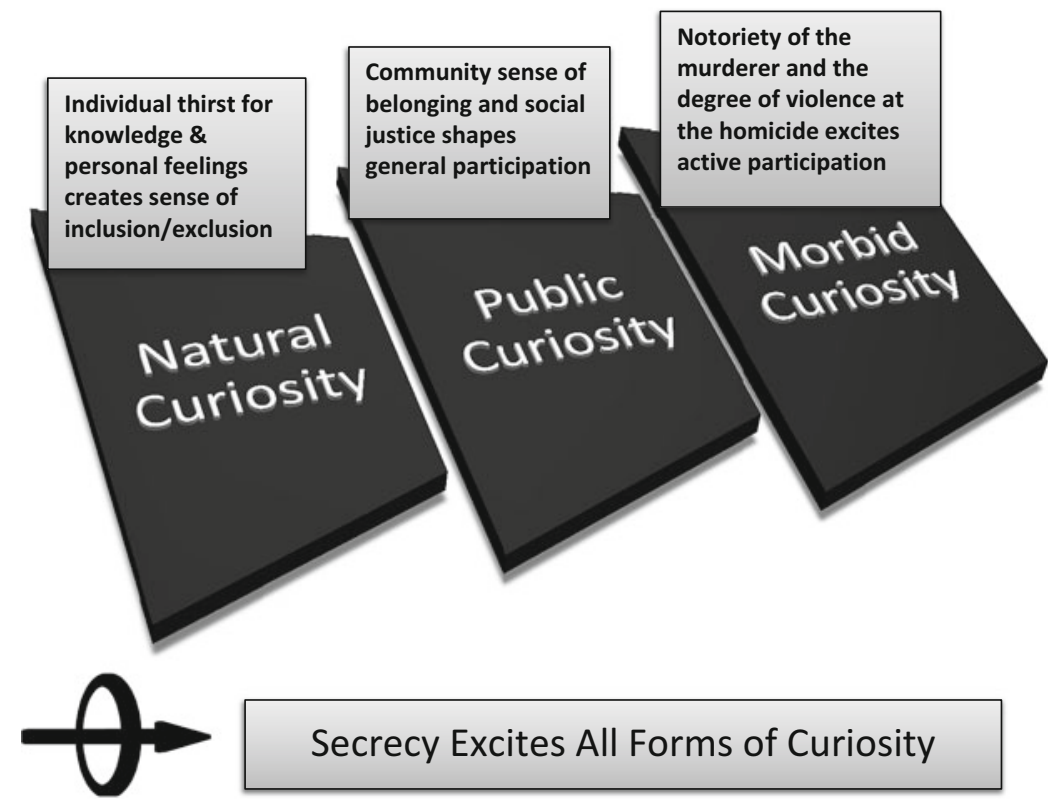

Figure 6.1 A new model of eighteenth- and nineteenth century curiosity at criminal dissections.

Encircling the paradigm is an early modern sense that 'secrecy excites curiosity' because to be curious is to recognise that there will be 'conflicting uses of curiosity made by different groups, often for crucial ends' ${ }^{28}$ State power seeks to suppress, but instead will often stimulate that which it fears, the forces of 'radical curiosity'. Such human reactions set in context why it was that at criminal dissections the actions of the crowd came to express on many occasions an insatiable curiosity that reflected narratives of beliefs, emotion, participation, exclusion and sentiments, commented on in contemporary newspapers. The key logistical issue for the early modern state was that in exciting all this 'popular curiosity' to stimulate support for capital punishment in the transition from a moral to political economy, there was little that legal officials and penal surgeons could do when that 'curiosity took on a life of its own, behaving in ways that no single person or institution could control, however much they tried' ${ }^{29}$ There 
Table 6.1 Audience participation activities at criminal dissections, 1752 to 1832

\begin{tabular}{|c|c|c|c|}
\hline Body, Condition & Penal Punishment & Official Status & Crowd, Agency \\
\hline Alive, Anti-mortem & Execution & Legal Death & Active, present \\
\hline Dead-Alive, Liminal & Anatomization & Medical Death & $\begin{array}{l}\text { Active, present to check } \\
\text { 'truly dead' }\end{array}$ \\
\hline $\begin{array}{l}\text { Truly Dead, Decay } \\
\text { \& Putrefaction }\end{array}$ & $\begin{array}{l}\text { Dissection, } \\
\text { Dismemberment }\end{array}$ & $\begin{array}{l}\text { Post-Mortem } \\
\text { penalty }\end{array}$ & $\begin{array}{l}\text { Active, but recoils \& } \\
\text { retreats }\end{array}$ \\
\hline $\begin{array}{l}\text { Curated Skeleton, } \\
\text { Skull \& Body Parts }\end{array}$ & Display & $\begin{array}{l}\text { Post-Mortem, } \\
\text { curated }\end{array}$ & $\begin{array}{l}\text { Active, returns to see } \\
\text { the spectacle }\end{array}$ \\
\hline
\end{tabular}

was only one practical solution under the circumstances and that was to make criminal dissection very offensive when taken to its logical conclusion. The 'perils of curiosity' had to somehow be deployed for political and professional ends, and a discourse on contagion, real and imagined, served this purpose well. There was thus a point in the dissection itself when the reality of the dirty, decaying corpse became very distasteful. The crowd retreated and, often quite sensibly so, until skeletons, skulls, and body-parts were brought back for display. We have then through the prism of the post-execution crowd's curiosity discovered a fourth step on the punishment journey of the Murder Act (Table 6.1):

Chapter 5 mapped provincial venues into four typologies covering different areas of England. These staged a medico-legal choreography that was fluid and framed by the four procedural steps identified above. Even so, there is one general point to keep in mind. Dissections were not a single event in the life of a community. They were usually medical performances staged on average over three consecutive days. This meant that the audience kept changing its profile. The execution crowd came first, they filed past, vacated the premises, but as there could be up to 25,000 people walking around the criminal body during day one there was no let-up in the number of those taking part in the initial ritual performance. If a body was hanged at noon, cut down at $1 \mathrm{pm}$, then the anatomization done by $2 \mathrm{pm}$, and the doors left over for the next ten hours to be closed at midnight, then in that timescale there could be as many as 40 people a minute (for a crowd of 25, 000), 20 a minute (for 10, 000), 10 a minute (for 5,000 ) and so on, walking past the body. It was a logistical headache 
to move people efficiently through a space, especially a gaol room or small dispensary, but challenging even in a Shire Hall reception area or dedicated dead-house of a voluntary hospital. If those in charge got the timing of the crowd control wrong then it could be chaos in minutes.

On day two, another audience of educated people from the local area had pre-purchased a ticket to gain entry to the medico-legal space. Again this might be as many as $\mathbf{5 0 0}$ wanting to walk past and then sitting down to see the start of a criminal dissection. As they were paying spectators the onus was on the surgeons to show say the brain and to take more time doing so. It helped that this second audience might not choose to stay all day; it really depended on the research interests of those conducting the dissection and what they elected to present over sessions lasting 2-3 hours typically. Occasionally at night women of the elite and middling sort might be permitted to attend an anatomy demonstration on day two (on say the eye, or face, or heart) but this would have a very different atmosphere from those which females of the labouring sort attended to stare at dangerous men laid out for their delectation. By day three, medical men from the vicinity were admitted exclusively, usually for surgical and scientific purposes, generally accompanied by their apprenticed pupils. Provincial dissections were therefore a product of the curious, educated, or research-driven interests of those pressing to see different daily sessions, and each depended on the age, gender and ethnicity of the criminal. At the end there was an opportunity for receiving back material afterlives to be studied, and once more the crowd entered to gaze. To reach what was soon dubbed the 'dead-end' of a criminal dissection thus looked like that in Figure 6.2 overleaf.

William Hey, a senior surgeon working at Leeds Infirmary carefully scheduled his criminal dissections to the basic timetable illustrated below. ${ }^{30}$ His private papers indicate that in the first hours after death he displayed the criminal corpse for crowds of up to twenty thousand people that accompanied a body sent from York to Leeds. Hey charged the audience a nominal price of 'three pence per visitor' to view the disreputable cadaver, but nobody was permitted to touch it, or take souvenirs like clothing or a body part. After the execution of Mary Bateman hanged at York for murder and witchcraft in March 1809, Hey said he raised a total of 'thirty pounds' at ' $3 \mathrm{~d}$ per person' from some ' 24,000 spectators' at the public viewings. Many people paid the nominal fee but the labouring poor were permitted to enter free-of-charge to prevent a public riot (sure to follow 


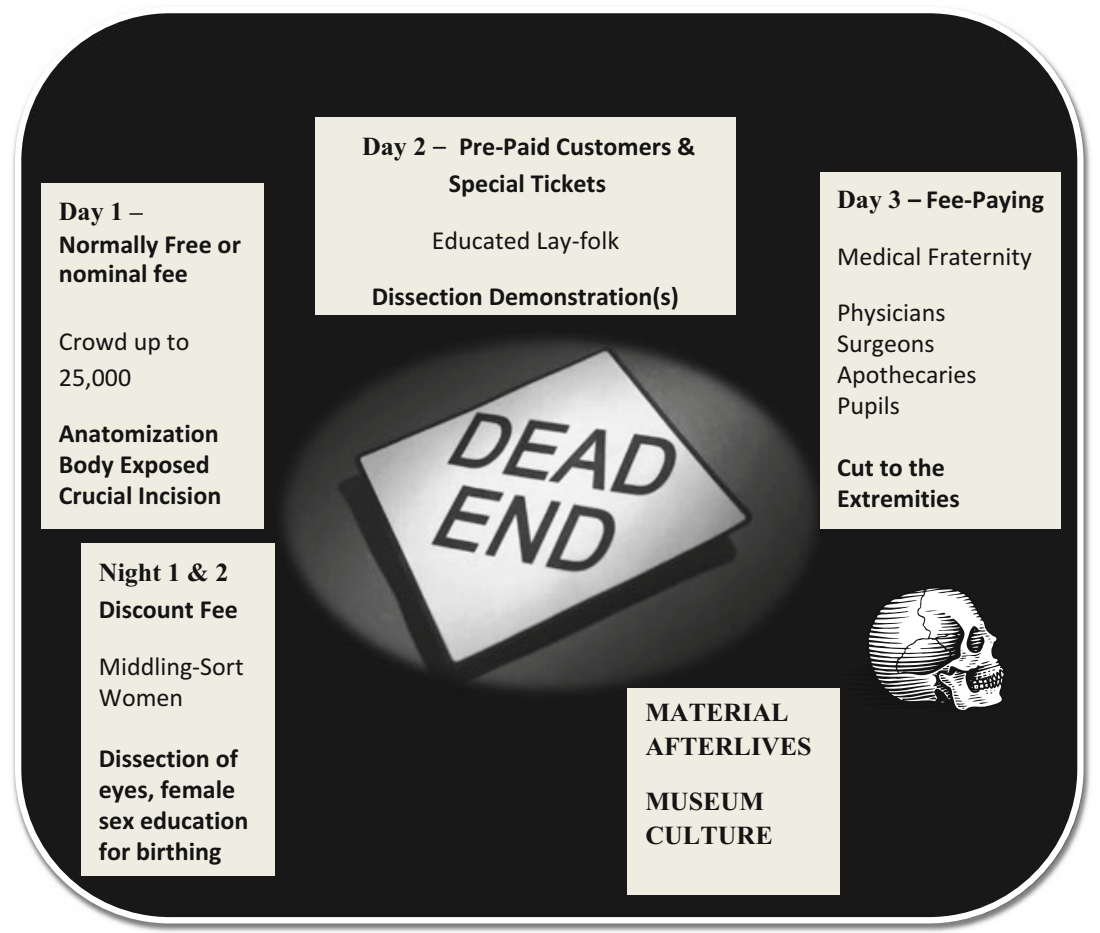

Figure 6.2 The Dead-End of the criminal corpse and its daily audiences.

had they been refused on the grounds of expense). On day one, people filed past the body at 40 per minute such was the level of local interest. They generated charitable monies donated to Leeds Infirmary: a clever ruse to minimise bad publicity.

Once the corpse looked lifeless, the crowd were then encouraged to take a respite and medical students came forward for a fee of ' $10 \mathrm{~s} 6 \mathrm{~d}$ each' to see the major organs expire. ${ }^{31}$ Hey's pay-as-you-view scheme was choreographed to ensure that ten surgeons and their apprenticed pupils from the vicinity moved to the front of a long queue once original research got underway on day two. Hey also had an eye to making more charitable profits and so he sold 'special tickets' to the professional men of Leeds: 'about 100 tickets were available to gentlemen who paid five 
guineas' each to see dissection of the muscles. Women could buy another type of discounted ticket for Hey's 'special lectures for ladies upon the eye', the 'windows of the soul', a fitting spectacle for female sensibilities. At the famous dissection of Mary Bateman, Hey thus banked a total of ' $£ 80 \mathrm{l4s} 0 \mathrm{~d}$ '. Altogether he timetabled three intensive dissection days, followed by 12 lecture weeks on her body, body parts, trunk, brain, and extremities. The York court recorder came across to see the entire sessions staged at Leeds: 'The curiosity excited by the singularity and atrocity of her crimes, extended to the viewing of her lifeless remains'. Here was the unpredictable nature of curiosity and the emotions it gave rise to, shaping the post-execution experience for the audience. There was something chilling, he wrote, 'gruesome', but 'fascinating' about 'seeing a body filled with guilt'. It was almost as if the inside of the corpse contained a latent power of its horrible earthly actions. William Hey insisted that medical students should overcome such feelings of horror to learn from 'a rational amusement'. Yet, his private notes record how he too was fascinated by 'the body of the malefactor ... entering largely into the physiological remarks, and more slightly into the diseases and accidents to which the various parts of the body were liable'. ${ }^{32}$ Dissection educated the medical mind and trained the irrational human senses in the face of criminal notoriety. In the provinces meantime similar profitmargins were made in the first 3-days at Cambridge, Manchester, and Preston (places we will be visiting later in this chapter). Alighting at Derby it is feasible to explore the underlying medico-legal and social tensions-between on the one hand the desire to drive forward original research-and on the other hand the need to somehow redress the discomfort many felt about the sorts of opportunity costs associated with being part of a criminal dissection. Although the anatomy of the criminal brain captured the general public's imagination, it also troubled medicolegal officialdom too. 


\section{Dissecting the Criminal Brain: The Nervous Energr OF ORIGINAL RESEARCH}

Next the long nerves unite their silver train, And young Sensation permeates the brain..$^{33}$

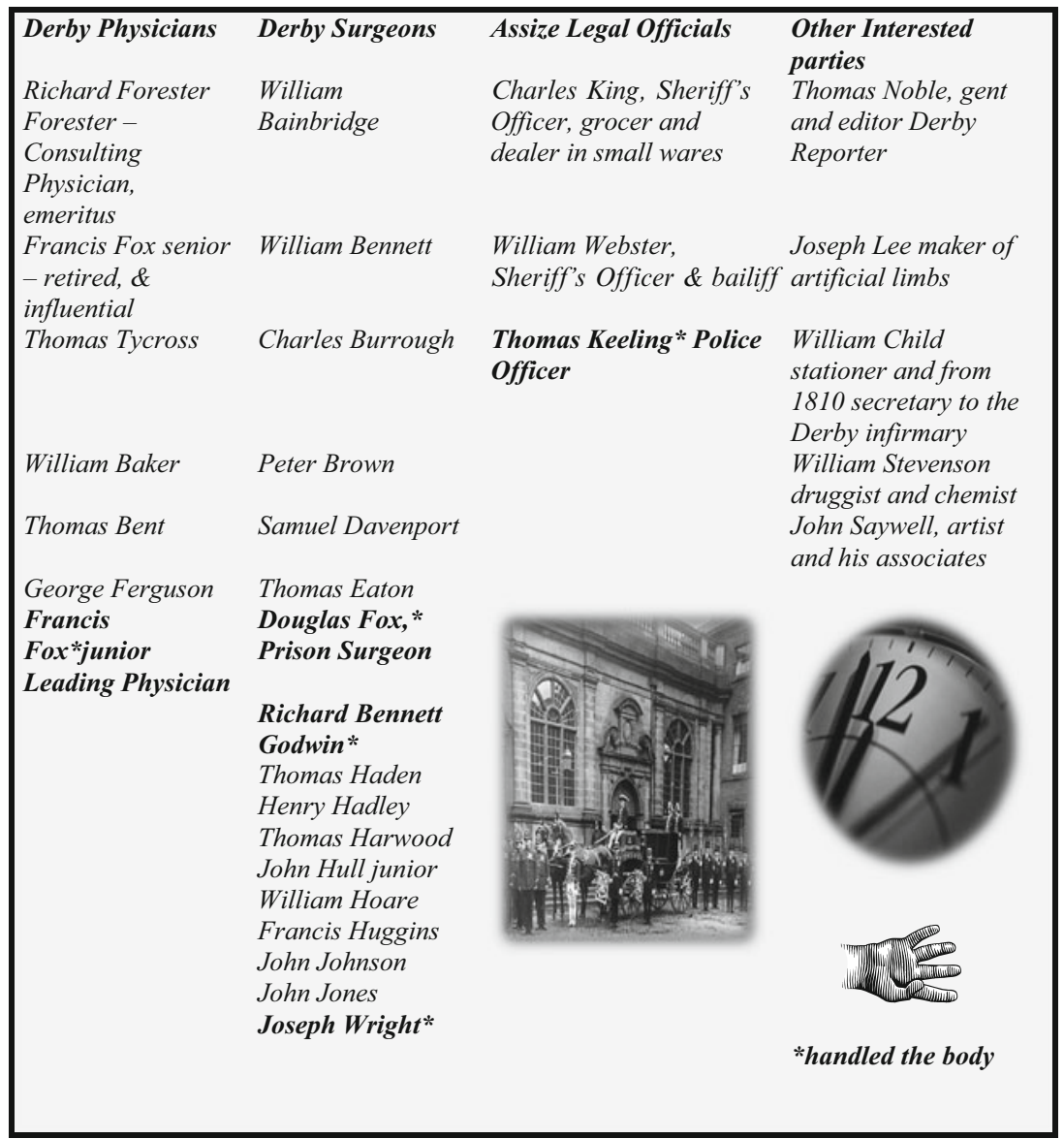

Figure 6.3 William Webster's corpse, dissection day, Derby, 1807 (Source: William Webster's corpse, dissection day, Derby, 1807, reconstruction of those present. Record linkage work compiled at Derbyshire Record Office on 'William Webster's Corpse, Dissection Day, March 1807, Derby Shire Hall'). 
At Derby, dissections that focused on brain function had become a respected research priority involving the criminal corpse by 1800 . Thus in a well-documented and representative case, when William Webster was convicted of murder at Derby Assizes on 20 March 1807 medicolegal officials and lay-people assembled together at his criminal dissection. Webster had 'poisoned to death Thomas Dakin, Elizabeth Dakin and Mary Roe'. The judge decreed that for a triple murder and such a despicable method of homicide-poison being the silent killer-his body must be delivered for extensive dissection. The designated venue was Derby Shire Hall (Derby Infirmary was not opened until 1810). Yet, events subsequently caused considerable controversy in the medical press. ${ }^{34}$

An array of medical men stood awaiting the body of William Webster in Derby town. Record linkage work reveals that there were seven physicians, seventeen surgeons, two legal officials connected to the sheriff's office, and six other interested parties, who had a right of access. All were anxious to have a hands-on experience (see, Figure 6.3, page 235). The actual dissection was done twenty-four hours after the death sentence by a leading physician (Francis Fox junior) and three surgeons (Richard Benet Godwin, Joseph Wright and Douglas Fox); as well as someone not named but described as an 'operator' (likely to have been one of the two sheriff's men present) tasked with shaving, washing the body and preparing the anatomical instruments. What primarily interested all the leading medical men in the town was the nervous energy in Webster's brain. The Medical and Physical Journal thus reported:

Many, medical men of Derby and its vicinity attended the dissection, and some were desirous of seeing the state of the brain in a person destroyed by hanging. It was therefore examined by the gentleman [physician] who conducted the dissection, who was very much accustomed to the task, and by others who were present. ${ }^{35}$

Brain research had been pursued at Derby since the Murder Act. As we saw in the previous chapter, Erasmus Darwin and his scientific circle in the Midlands stimulated a lot of ambitious research on the function of the brain. Their work was being talked about in the town and its vicinity. In William Webster's case, Francis Fox junior, the leading Derby physician in 1807, raised his dissection instruments to cut the top off the skull. Fox had established his reputation in the town by attending Erasmus Darwin in his final illness in $1802 .{ }^{36} \mathrm{He}$ had also been doing criminal dissections 
in the Midlands since the 1770s, as we again saw in the last two chapters. A local Derby history published in 1829 thus described Francis Fox as: a 'physician, philosopher and chemist' who by 'superior talent is rising into considerable eminence'. ${ }^{37} \mathrm{He}$ was ably assisted by Douglas Fox the leading surgeon in the town who 'filled the situation as Surgeon to the County Prison some years with universal satisfaction to the Magistrates of the County and the prisoners under his care'.

By tradition the hangman in Derby completed the death sentence either on or behind the gallows. 'John Crossland the infamous hangman' until 1705 was said to have had responsibility for: 'The bodies of the executed were his prerequisite; signs of life have been known to return after execution; in which case, he prevented the growing existence by violence'. ${ }^{38}$ After the Murder Act the responsibility for legal death remained with the Derby hangman in $\mathbf{1 7 5 2}$ but the task of medical death was delegated to the prison surgeon who assisted the Sheriff. This meant that over a timespan of five decades once the capital legislation was passed, Francis Fox and Douglas Fox were well-versed in handling condemned men and medical death by $1807 .{ }^{39}$ They knew how to act efficiently post-execution. In this, Francis seems to have been influenced by Erasmus Darwin, his private patient, and fellow physician. Darwin had long been fascinated by the 'sensorium of the mind':

The word sensorium is used to express not only the medullary part of the brain, spinal marrow, nerves, organs of sense and muscles, but also at the same time that living principle, or spirit of animation, which resides throughout the body, without being cognizable to our senses except by its effects. ${ }^{40}$

On the boundaries of life and death, especially in extremis at executions, Darwin claimed that medical men must be alert to the physical fact that dying could be prolonged and protracted because contraction of the sensorium in the mind might be slow until a physical state of general diminution was reached. ${ }^{41}$ Or, it might only result in partial diminution causing a state of suspended animation; worse still, in a criminal it might go into reverse, looking dead, but actually be a form of extreme cold in which an accumulation of the sensorium was happening as the brain rested to recover its powers. At a time when galvanism, resuscitation, and suspended animation were very fashionable topics, the dissection room was where the boundaries of life/death might be glimpsed together. ${ }^{42}$ Against this intel- 
lectual backdrop William Webster's dissection was attended with considerable publicity in 1807 .

The medical press noted that although everyone present agreed about the need to conduct original research on the dissection of the criminal brain in Derby, there were differences of opinion about how much experimentation figured under the original Murder Act. It was understood that post-mortem 'harm' was intended but the medical limits of potential human vivisection in the criminal brain remained controversial. An onlooker wrote to the Medical and Physical Journal on 26 August 1807 admitting in print that he 'had some awkward feelings' which he kept to himself during the dissection of William Webster. ${ }^{43} \mathrm{He}$ claimed that he did not walk out or intervene with the experimentation because 'he did not conceive himself in a situation to interfere'. This stance was ridiculed by the London press. In the capital surgeons questioned whether provincial practitioners should be permitted to attend criminal dissections if they were so ill-qualified to remark upon them. At Surgeon's Hall leading men like Sir William Blizard had pioneered criminal craniotomy, ran one robust reply from a London correspondent. He went on with bitter satire to challenge the rather conventional attitude of some provincial practitioners who had access to brain dissections at Derby and places like it-'I dare say that he had some awkward feelings of incapacity and inferiority'. Angered by the insinuation that local doctors were second-rate, the same 'Derby practitioner' in a follow-up letter went on the offensive in the medical press: 'I am well able to prove that this dissection, as it respects the brain, was not conducted on the principles of scientific anatomy' but out of consideration to his profession he chose not to elaborate further in print. ${ }^{44}$ There was a lot of dispute by 1807 as to whether heart-lung failure, strangulation by the rope, or brain death, marked the end of dangerous criminals. This was an open field in which medical men in the Midlands could make their reputations through original research. Each dissection venue thus became the site of speculation about the anatomy of the brain because it had ignited so much curiosity in nearby towns and cities. The criminal body became a benchmark for competing research agendas but whether this was what the legislation had intended was open to dispute.

In order to do brain-research penal surgeons at a criminal dissection had to make a basic decision. If they needed a skeleton for teaching purposes then there was little point in dissecting the head because it would destroy the skull. At Bury St, Edmunds it is worth recalling that at William 
Corder's dissection in 1827 a decision was taken to preserve his skeleton and so his brain was left in-tact. ${ }^{45} \mathrm{~A}$ cast was taken of his head and a phrenology examination made of its anatomical profile; likewise his corpse was skinned, and minute study was made of the muscles; but brain research was ruled out. This contrasts with Leicester Infirmary where medical men were excited by the sort of original brain dissections that were being done at Derby. ${ }^{46}$ Today neurology is seen as a discipline of modernity ${ }^{47}$ but it is possible to date its recognisably scientific research-stirrings to a selection of criminal brain dissections between 1807 and 1815 across the Midlands. This was a time when many provincial places started to specialize in vitality which in turn gave rise to a lot of disquiet about access to, and privilege knowledge of, original research on criminal heads. This debate was of course nothing new because from 1752 medical men had been expressing anxiety about the prurient interest of the crowds that accompanied the post-execution body. Yet, as brain death replaced heart-lung failure as an explanation for the boundaries of life/death there was a groundswell of opinion that only scientific eyes should be permitted to partake. At Leicester Infirmary on 23 March 1822 it was thus resolved that: 'the practice of exhibiting bodies of unfortunate persons given to the Infirmary for dissection appeared to us improper, and that in future no such public exhibition be permitted'. ${ }^{48}$ This Midlands attitude was influential elsewhere. By 1827 the Royal Devon and Exeter Hospital followed suit declaring that the viewing of criminal corpses 'so much enjoyed by strangers... should be permitted only on the day of execution', and the 'doors be closed once dissection commenced'. ${ }^{49}$ It would be a mistake however to conclude that generally crowds were excluded given what contemporary newspapers revealed in Section 1 of this chapter.

Popular Sunday journals like The Age explained that 'morbid curiosity' was a feature of many dissection venues and inside it was very difficult to control or predict. Often it was related to the criminal's visual appearance at a time when disease was said to make an appearance on the body. Returning briefly to the criminal dissection of murderers like Alexander Keand from Section 1 above, what dangerous criminals looked like physically when apprehended featured prominently in the reporting of postmortem 'harm'. The Age elaborated on why Keand was such an intriguing anatomical subject: 'Alexander is 5 foot 7 inches, dark eyes, whiskers, broad set...generally wears gloves on his hands being scrofulous and scaly, and his nails bitten black at the bottom'. ${ }^{50}$ The Sunday edition of The Observer 
newspaper meanwhile decided to publish some letters from medical correspondents elaborating on Alexander's brain dissection. Peering inside, his anatomy was normal but he had committed an abnormal crime; a disturbing finding. The Lancaster dissectors therefore agreed to two unnamed but respected local phrenologists preparing a separate report which was widely publicized for its 'moral' as well as 'scientific' value:

The phrenologists have found, in the construction of Keand's head [Alexander] further evidence to support their system. His devotion in gaol [to his brother Michael] is explained by the singular prominence of the organ of veneration. His desperate resistance when taken into custody and the fight between the brothers on the first night after their apprehension are referred to the extraordinary development of the organ of combativeness, and his murderous propensity rendered evident by the fullness of the organ of destructiveness. ${ }^{51}$

Artistic sketches were also taken of Alexander's physiology but the Manchester Guardian reporter warned readers that 'the portraits that have been published do not resemble [him] at all' ${ }^{52}$ The prison surgeon instead noted that both Keand brothers had 'dark complexions and dark eyes' and spoke in 'a strong Scottish accent' (they came from Dumfries but moved for business reasons to the Manchester area). These characteristics were said to have added to their sense of menace. Evidence like this pieced together from a variety of reporting sources enables us to stand to one side of the crowd as they paraded past Alexander Keand in the yard of the Lancaster infirmary where he was laid out on a portable dissection table to view. He was not tall, slightly above the average height of a woman, muscular, with a stocky build. We learn he was hirsute with moustache whiskers but only his dark stubble would have visible after being shaved all over. He probably had some form of eczema, psoriasis or ring-worm, given how scaly his hands looked. His nails were bitten to stumps and blackened. Alexander had been a hawker. His sallow skin may therefore have been an occupational hazard, tanned from travelling the dusty roads in warmer weather-beaten climes. His facial expression was described as 'not prepossessing'. It was his ordinariness that was so disturbing, despite the various newspaper reports that took dramatic license with Alexander's determination to resist arrest, indifferent courtroom demeanour, and unrepentant final hours. Cases such as this and many like it in the archives 
explain why dissectors wanted to get inside the criminal brain. A logistical issue that had to be resolved was how to satisfy the 'natural curiosity' of the crowd to create a legal deterrent yet without fanning either 'morbid' or 'public curiosity' to such an extent that the agency of the crowd could overwhelm medico-legal officialdom. The question of the theatrical features of the criminal dissection showcase had therefore to be chosen carefully in situ.

Penal surgeons soon concluded that to do their public duty they had to enact a performance of criminal justice by staging retribution as an immersive form of theatre. This involved permitting the crowd to be in close proximity and looking carefully at the corpse often at arms-length. Yet, equally they had to grapple with the practical problem of what they could visibly actually show their audiences walking around the condemned body. When heart-lung failure was the standard explanation for medical death it was a physical shut-down open to everyone. Brain death happened deep inside the head and lacked visibility. It was much less accessible to laypeople, and yet potentially a very exciting area of new medical research. In satisfying the crowd that the criminal was a corpse about to be punished, penal surgeons lacked a graphic method of showing how the brain had died. In a craniotomy the top of the skull was sawn off and skilfully so, but what everyone was looking at in terms of grey matter remained mysterious. So increasingly many penal surgeons welcomed phrenologists and engaged in experimental work to try to ring-fence their medico-legal standing. A well-known example from Cambridge is illustrative of these brain research trends and the continuing role of the crowd's curiosity in shaping the choreography of criminal dissections.

The execution of Thomas Weems for murder on 6 August 1819 has become very famous in criminal histories. ${ }^{53}$ His condemned body was subjected to a number of quasi-scientific experiments to explore the nature of electricity, resuscitation, and brain death, all associated with Mary Shelley's Frankenstein (1818). The homicide circumstances were akin to those of the John Holloway copycat killing of his rejected wife in Chapter 3 . Weems had been compelled by parish officers to marry a young woman called Mary Ann whom he courted and allegedly got pregnant. After they were married she said that she had miscarried, but he did not believe her thinking he had been tricked. On his business travels (he was a miller) he met Maria Woodward a pretty girl from Edmonton in Bedfordshire. They started walking out together, fell in love, and he wanted to marry her, but was not free to do so. Before long, in despair he decided to murder his 
wife. Weems strangled Mary Ann, left her for dead in a shallow field-ditch, but was seen running away, arrested and apprehended by a local magistrate near Godmanchester in Huntingdonshire. General opinion held that his crime must fit the punishment, for he had 'with a garter...tied a slipping noose' around the victim's neck 'round which was a black mark' when it was removed. Murdering her by duplicating an execution method was for many local people unforgiveable. This context explains why there was so little sympathy expressed in the local press for the extensive nature of the post-mortem punishment rites at Cambridge where he was tried and found guilty of murder.

Weems was executed at 'a few minutes past noon' over the 'gateway of the county Gaol'. ${ }^{54}$ An hour later he was cut down and paraded through the streets of Cambridge to the Botanic Gardens. These were at the time located next to a purpose-built anatomy theatre in the town-centre along Downing Street. By $1.45 \mathrm{pm}$ a reporter from the Cambridge Chronicle was on hand to record what happened next:

Friday 6 August 1819 -

The body, after being suspended an hour...was immediately conveyed in a cart to the Chemical Lecture-room of the Botanical Garden, where Professor Cumming had prepared a powerful galvanic battery (which formerly belonged to Professor Tennet) with the intention of repeating some of the experiments lately described by Dr Ure of Glasgow in the Journal of the Royal Institution. ${ }^{55}$

He then went on to describe how the usual anatomization procedure fused with a number of experimental research methods. They involved applying to various parts of the body some ' 220 pairs of double six inch plates charged with dilute sulphuric and fuming nitrous acid' to give the galvanic batteries 'intense action'. These were as follows:

Experiment 1 - One wire was applied to a small incision in the skin of the neck over the par vagum [pair of vegas nerves], and the other one made between the 6th and 7th rib; when at each discharge of the battery, the chest was disturbed in a manner similar to a slight shuddering from the cold; the period of shuddering corresponding to the number of plates struck by the operator in the trough.

Experiment 2 - The par vagum [pair of vegas nerves] was laid bare, and one of the wires passed under it; the other was placed in contact with the 
diaphragm, through an incision made deeper between the 6th and 7th rib. The contractions were evidently stronger than in the last experiment, and to all appearances confined to the same set of muscles. Not the smallest action of the diaphragm was perceptible. ${ }^{56}$

Experiment 4 was done on the 'supra-orbitary nerve' to see if there were any 'mental afflictions', but instead what happened physically was described as 'convulsive twitching'. Experiment 6 involved connecting up the legs and arms to see if they could be revived; whereas experiment 7 explored electricity and the 'spinal marrow'. All the experiments lasted together 'about an hour' until $2.45 \mathrm{pm}$. Throughout the body temperature was recorded at '93 degrees' because the corpse was so fresh and it was summer. It was commented on that 'there was no dislocation of the neck' and 'no distortion of the countenance' either post-execution on arrival, or after the experiments. In other words, the body was in a good condition, could potentially have cheated medical death, and so was ideal for original research of this nature. Only once the experiments had been carried out, were 'the necessary dissections...executed by Mr. Okes in the presence of nearly all the medical men in Cambridge, many members of the University, and several of the most respectable inhabitants of the town and country'. ${ }^{57}$ In all likelihood this was akin to splanchnology because the initial anatomization cuts were rather superficial, being subsumed with the experimental work to see if resuscitation was feasible. The exclusion of the crowd however from the spectacle was being talked about across town and did cause considerable disquiet. Questions were being asked in the local press about just how extensive was the dissection and what would happen next. The crowd were determined to have their curiosity satisfied.

The following day, Saturday, 'the body was exposed to public view in the same room in which the experiments had been performed'. To try to control the situation, 'Constables were placed at the gate of Downingstreet, to prevent the room from being too much crowded, and the doors were opened from 12 noon' to the crowd. Reporters said:

The benches were instantly filled with spectators, whose countenances bespoke a strange combination of curiosity, disgust, and awe. Crowds of every description of persons continually succeeded each other until one o'clock and amongst the many hundreds who came to view the body, no one seemed moved by a feeling of pity for the fate of the criminal, so strong were the grounds for his condemnation. The doors were then shut, and at a 
request of a large party of gentlemen, Mr Okes commenced a more extensive dissection of the body. ${ }^{58}$

By 1819 the medico-legal choreography that this book has retraced was well-known to a gaol surgeon like Mr. Okes working for Cambridge Castle. It was connected in the popular imagination to resuscitation checks and only then was dissection done by degrees, first splanchnology, and then cutting to the extremities. ${ }^{59}$ The medical fraternity had wanted to exclude the crowd to gain control of their research interests but they could not risk doing so exclusively because of the threat of public riot. Ordinary people of 'every description' remained interested, curious, but also repelled by the disintegration of the criminal corpse in Cambridge. In this case, they did not protest at being asked to leave once they had seen the criminal cut open. The body was still in a state to recognise its face from the execution as they departed. The constables on duty guarding the body could not turn away 'many hundreds' without extra logistical support, but they also did not have to do so. The crowd exited and then the doors were shut. All was orderly since what happened next would look less than human, a bloody mess. Yet, there was one last piece of the jigsaw puzzle of human identity left over. At Trinity College a square piece of white-coloured skin was preserved and sent to the University bookbinder. Handling this criminal corpse became about rebinding fragments of the dissolute, dangerous, dead into a skin-hardcover of a book shelved for posterity in Sir Christopher Wren's library. Before though examining those material afterlives in more detail, it is essential to first think about how this type of original research started to reshape medical education and where exactly the newly qualified felt they had to relocate to get on the career ladder in eighteenth-century England.

\section{A Disintegrating Corpse: The SCience of EXtremities \\ "In Mr Brooke's dissection room it was mutilated by the dissection knife" The Guardian, 8 April 1822}

Around the 1790s Thomas Bishopp, a medical student, wrote a series of letters to his near relations at Cold Overton in Leicestershire. ${ }^{60} \mathrm{He}$ explained about how his dissection training had progressed during the winter sessions after the Murder Act. Bishopp attended St Thomas's Hospital as a pupil apprentice in the day. At night he paid to learn about anatomy, 
dissection, and midwifery at private classes. Like many medical students at the time he thus wrote that he was 'a walking pupil' on the hospital wards. ${ }^{61}$ From November 1792 he also described in detail how he had 'entered to the dissecting room, engaged for a subject, purchased a case of knives \& ordered the necessary dress'. ${ }^{22}$ The penal surgeons of London, he reported, had 'met with [the] difficulty of procuring bodies' by the 1790s because the murder rate could not keep pace with anatomical demand. ${ }^{63}$ Original research had become the raison d'etre of the most ambitious surgeons and like many Bishopp paid to attend very crowded extra dissection lessons in 'Leicester Square' and on 'Windmill Street' around Soho where the Hunters conducted their famous anatomical classes. Bishopp needed though to ask for family money to be sent by return post to pay for body parts supplied from the gallows or illegally from graveyards. In April 1794 he thus wrote 'concerning his dissection of part of an extremity' that had become available and that 'Mr [Richard] Tookey [House Surgeon St George's hospital] had also given him the opportunity to acquire 'an extremity of a child [for dissection] \& would I believe have given me more if they had not been so much distressed for subjects at Windmill Street where the dissecting room is' ${ }^{64}$ Evidence like this provides a window into a secretive world filled with curiosity and sets in context that 'dissection of the extremities and to the extremities' was standard on criminal corpses and resurrected body parts. By the close of 1794 Bishopp explained to his family that their financial support had not been in vain, for:

I shall be sufficiently acquainted with practical dissection \& anatomy to undertake all the common operations in surgery with good confidence in my qualification and I am not at all doubtful but that I understand the theory and practical department of midwifery as well as the majority of those who settle in the country. ${ }^{65}$

Here was a typical medical student preparing for provincial practice and trying to build a reputation for being skilled with the lancet whilst there was the opportunity to do criminal dissections in London. It was also important to remain mindful of the best places to learn to specialise in more original research. In terms of maximising future business acumen, the choice of the Midlands made sense since, as we have seen at Derby, reputations were being made because of better access to criminal dissections. Two strategic decisions taken by Bishopp at a formative career-stage illuminate the specialised medical market taking shape by the 1790s. 
In October 1792, Thomas Bishopp, on first qualifying in medicine, took the opportunity to become an assistant to 'Dr Robert Chessher of Hinckley' (1750-1831). His medical employer and mentor was busy building an unparalleled reputation as the first really skilled orthopaedic surgeon in eighteenth-century England. The anatomical study of criminal bones gave men like Chessher the opportunity for original research on the 'mechanics of the extremities'. In particular, he specialised in spinal conditions and limb injuries. It is noteworthy that Chessher was the grandson of Lewis Whalley, a respected physician in Lancaster whom we encountered in Chapter 5 (see, page 190) working on criminal dissections in the North West. Knowledge of the criminal skull, spine, and bones, was in circulation between the provinces through family, as well as, professional medical networks. Thomas Bishopp was consequently typical of the sort of medical student who sought to advance his career by association with established experts. He subsequently took a decision in 1795 to return for a year to London for further his anatomical studies. This however did not resolve the question of how best to get started in business because he had to start earning to pay off his student debts accumulated from his expensive education.

Thomas Bishopp was a financial realist, recognising that the London medical scene was very competitive and overcrowded. His career strategy was therefore to buy into a provincial practice once he had experienced enough dissections and acquired skills in midwifery. In 1797 he wrote to John Frewen of Cold Overton, his wealthy cousin, that he had the 'prospect of purchasing a third share in Dr Chessher's practice' but was unsure whether to proceed given how hard it would be to make it financially viable in a small town such as Hinckley. ${ }^{66}$ In the meantime he took on a fee-paying apprentice called 'Mr Beale' but the relationship turned sour because he proved to be lazy and devious about money:

I am now persuaded that he means merely to deceive his friends. I have perhaps seen him 3 or 4 hours in one day in three, but certainly not more, although I call on him more frequently \& have repeatedly told him to meet me at the proper hour every morning, where he goes to I know not nor can I undertake the care of him under these circumstances. ${ }^{67}$

Meantime, Bishopp was exploring 'the possibility of his purchasing [Edward] Le Grand's surgeon and apothecary's business at Canterbury', but again he had no luck. ${ }^{68}$ To tide himself over financially after the protracted business negotiations, he took up a Frewen family offer to become 
surgeon to the Sapcote Sick Club in September 1799 near Cold Overton. By all accounts this then helped him to secure his own practice at Friar Lane in Leicester by 1800. It was hard work at first, for in 1802 he wrote home that: 'I fear I have little ground to boast, looking only to the better class of the trading part of the town'. ${ }^{69}$ That final move brought him into the ambit of medical men working on the dissection of criminal brains and the fascinating subject of medical death and resuscitation in the Midlands.

By 1806 Thomas Bishopp was apologising for not writing to his relatives as often as he should because he had been very busy attending his private patients and trying to do original research in and around Leicester. He was intrigued for instance by new resuscitation techniques on attempted suicides: 'when I should have written to you, I was engaged in attempting to restore to life a young woman, servant to [Samuel Cheeke] Morris the surgeon [of Market Street Leicester], who had hanged herself' ${ }^{70}$ Living as he did in close proximity to the infirmary used for criminal dissections and coroners' cases, there was ample opportunity to make his medical mark in Leicester. Evidently this was beneficial for his reputation since he was delighted to report to his family sponsors that his business was buoyant with referrals. His growing reputation for innovation meant that: 'I will need to take on another apprentice, in a year or so'. Yet the credit control of fee-paying patients was a constant financial headache, and so he often had to take calculated risks. One further career move was therefore considered advantageous. Bishop was determined to apply for the position of surgeon to 'one or both of the gaols in Leicester' where he would have direct access to executed bodies and be paid a fixed-salary for prisonerconsultations. ${ }^{71}$ His ambitions culminated in a letter dated 13 February in 1807 in which he thanked John Frewen warmly for his local patronage and was pleased to confirm that he had established his medical-standing in the Midlands.

Evidence like this private correspondence indicates that doctoring could be a steady occupation, but there was the ongoing problem of managing fickle consumer demand. It was imperative to stay ahead of the competition. It is noteworthy that John Bishopp's gains at Leicester were still fragile in 1807, for instance, hence he had to fall back on his Poor Law work: 'my pressure of business is of course very irregular \& unsteady, otherwise I should think soon of giving up the care of All Saints Parish poor' in the town-centre. He admitted moreover that: 'I have been engaged with the poor when I have wanted for better patients'. ${ }^{72}$ Gaining access to criminal bodies by becoming a gaol surgeon was there- 
Table 6.2 Location of criminal dissections and their respective research activities by 1800

\begin{tabular}{|c|c|}
\hline Location & Dissection Activity \\
\hline Birmingham & Surgical amputations and trepanning of the skull \\
\hline Bristol & Dissection of heart/lung/brain and midwifery \\
\hline Bury St Edmunds & Muscles, heart-lung capacity, phrenology of head \\
\hline Cambridge & Nerves, Galvanism, Spina Bifida \\
\hline Colchester & Medical death, phrenology of head \\
\hline Derby & Brain vitality \& sensorium (nerves) \\
\hline Hinckley & Bones \& Orthopaedics of limbs and back \\
\hline Ipswich & Gonorrhoea, Heart resuscitation, breast tissue \\
\hline Leeds & Structure of the eye, hernia, limb amputations \\
\hline Leicester & Brain research and medical death \\
\hline Newcastle & Dentistry o morbid diseases of the coal industry \\
\hline Northampton & Blood flow, mechanical physiology es secretions \\
\hline Norwich & Skeleton, phrenology of head \\
\hline Nottingham & Skeleton, phrenology of head \\
\hline Plymouth & Skeleton, phrenology of head \\
\hline Salisbury/Winchester & Fever, nerves, kidney \& military wounds \\
\hline York & Treatment of madness and maladies of the mind \\
\hline
\end{tabular}

fore a smart business move, embodying accessibility, exclusivity, and status. Against this backdrop, medical men in the Midlands tended to try to align closely with the criminal justice system, even though working on executed bodies might tarnish their public image. The opportunities criminal dissection afforded to develop a growing reputation for innovation out-weighed sensitive public relations considerations with regard to the post-execution crowd.

After the Murder Act the type of original research being done on criminal dissections was to gradually influence where ambitious new surgeons sought to locate themselves provided local business opportunities were favourable: the Table 6.2 above indicates key locations and the sorts of specialisms gaining a foothold. There was no distinctive regional patterning to particular types of anatomical interests, unlike the dissection venues in Map 5.1 page 183. The reason for this trend was that it really depended on the availability of criminal body types (age, gender, height and so on), and what then was feasible for local surgeons to do in terms of using dedicated dissection space. This influenced how their work related to the wider medical marketplace on location. Many wanted to pursue individual research but they had to be opportunists as most were working 
in environments where scientific endeavour had to be paid for from business profits. If the executed criminal was very muscular, for instance, it made sense to dissect the musculature in minute detail. If the crime was a particularly gruesome homicide then a phrenology cast was usually taken because the brain was the focus of intense interest. All of this type of postmortem work nonetheless involved taking apart the corpse by dissection and dismemberment unless the skeleton was the main object. An added complication was that medical students sometimes argued about getting access to what were regarded as trophy heads to dissect. The Morning Post of 15 September 1819 reported one such compliant that came before the Middlesex Sessions:

Mr James Luke, a young Gentleman, and one of the students of the London hospital was indicted for committing an assault on Mr Charles Roberts a fellow student, on the 7th June last in the Dissecting Room. Mr Charles Roberts, the Prosecutor, said the Defendant and himself were house pupils in the London Hospital when a misunderstanding arose upon the dissection of a body. He was desirous, with a Mr Parrot of dissecting the brain, and Mr Luke said he had been told by Mr Andrews the surgeon, that the Prosecutor's skill was equal to the task. He saw Mr Andrew's who disclaimed having said anything of the kind. The assault took place two hours after. The Defendant, in the dissecting room, clenched his fist, and said he should like to lay both, meaning the Prosecutor and Mr Parrot flat on the floor...The Defendant struck the Prosecutor with a violent blow to the stomach. ${ }^{73}$

Evidence was heard from a senior surgeon that Mr Charles Roberts was not telling the truth. He should not have been dissecting the brain because it had been left for a coroner and experienced surgeon to examine. Then he stated that in any case dissecting a criminal head was 'a task too delicate for a young man like the Prosecutor who had been no more than six months at the hospital'. The Judge urged Roberts to apologise to Luke, and asked the latter to make a charitable donation of ' $10 /$ ' to the Hospital. He reminded them that their behaviour spoke of 'indecorum in a place which may be called a place of education'. They shook hands and the case was dismissed. Yet, the vignette was telling. Questions of medical competency, competition to dissect brains, and a general fascination with the criminal mind, were all aspects of dissection work that was secretive but excited public curiosity. Standard techniques were well-known by the 1810 s from anatomical books and manuals, but there was a lot of practical information withheld from the general public about what amounted to an 
'insatiable curiosity' for the torso and head-piece. One example stands in for many from the archives.

On 8 April 1822 a civil case, King versus Cundice, was brought before the Surrey Assizes. It exposed in court what it meant to dissect and disintegrate a dead body convicted of a capital offence. In the case's opening remarks the prosecution declared that: 'the science of anatomy was most beneficial to mankind; but, its advancement ought not to be attained by the violation of those feelings which were the most scrupulous in the human breast'. ${ }^{74}$ The facts were that a highwayman named Edward Lee was tried and found guilty of a capital offence. He was hanged and then his body was to be buried by 'William Walter, the keeper of Horsemongerlane gaol'. He took a decision to delegate the internment to 'Edward Cundice, the undertaker' to be done in a 'decent and proper manner'. Walter was 'paid out of the rates of the county of Surrey' to do the burial recouped from gaol funds. Cundice however pocketed the money and sold on the body for dissection. The Judge had ordered that although Lee had not committed murder his body must still be anatomized. This was to make sure the convict underwent medical death, but he also stressed that it must not be dissected. Cundice ignored this stipulation and made a business deal with 'Mr Brooke's the anatomist' because supply-lines were low and there was a valuable profit to be made from the sale. In the course of giving evidence in a subsequent civil case about what happened at a criminal dissection the prosecuting counsel revealed that:

Edward Lee was tried in Croydon on 23rd August and executed on the 10th September. The defendant Cundice was undertaker to the gaol and did all the carpenter's work... Three guineas was paid to the defendant for the burial... The body was traced to Brooke's dissection rooms where the body had been mutilated by the dissection knife. ${ }^{75}$

Local gossip alerted the family of the deceased that a false burial was staged and they called in 'James Glenman a police officer' who:

Proved that he had made search after the body of Edward Lee and at length found it at Mr Brooke's dissecting rooms in Blenheim Street, Marlboroughstreet. The body had been operated upon; the top of the skull had been cut off but replaced. He was quite satisfied that it was the body of Edward Lee. On one arm was the initial E.L. tattooed with gunpowder. ${ }^{76}$ 
The body had been transported from the Surrey Assizes to be sold to a private anatomy school run for fee-paying students by Mr Joshua Brookes near Oxford Street in central London. Cundice defended that he had been duped. He claimed that the body had been stolen at night from his undertaking premises when he was asleep. As the victim of a dreadful trade, he panicked covering up the burglary with a false funeral. The defendant's counsel criticized the fact that 'Mr Brookes the imminent anatomist' and 'Fellow of the Royal College of Surgeons' was not being called to give evidence. The judge had already directed to the jury that official enquiries had been made informally. He decreed that the Crown was satisfied that he 'was not trafficking in human flesh' but had taken advantage of a gallows body becoming available which was not illegal. The view taken in court was that burying a coffin that 'contained nothing but earth' in capital offence cases was a common undertaking swindle. Sentiments were running high in final speeches to the jury: 'Reverence for the ashes of the dead was so deeply implanted in the human heart, that it was impossible upon such an occasion not to feel something like prejudice where its sanctity had been violated'. Despite an appeal by the defending barrister to consider the objective facts, Cundice was found guilty. He was sentenced to 6 months in prison for his undertaking scam. His successful conviction revealed that in all types of capital cases corpses were being sold for 'three guineas profit' by the 1820s. The extremities, marked by tattoos were 'mutilated' on the dissection table; the head was decapitated, placed back on top of the torso so a skeleton could be made. This type of material afterlife was often controversial, not just in the capital, but rural areas too, where we see equivalent examples occurring throughout Eastern counties.

In 1771, the Norwich and Norfolk Voluntary hospital was established for the treatment of the sick poor by voluntary subscriptions. By the 1790s when 'new anatomy' was being promoted in East Anglia the board met to decide what to do about requests to stage criminal dissections on their premises to further original research. On 12 August 1797 the governors thus stated: It is 'Ordered that the Physicians and Surgeons be requested to take into consideration the propriety of dissecting bodies at the hospital removed thither for that purpose'.$^{77}$ It was evidently not a foregone conclusion that when a judge sentenced someone to be dissected it would automatically happen where the legal authorities intended. This particular ruling gave rise to considerable medico-legal debate because on 19 August, seven days later, another clarification was made by the hospital board: 
August 191797 - Ordered that no Malefactors shall be brought to the hospital for dissection without the consent of the majority of the physicians and surgeons at this hospital, such written consent to be lain before the next weekly board and entered amount the orders of that board. ${ }^{78}$

Yet it would be a mistake to take this situation either at face value or to regard it is as stable and unchanging. By the 1810s there was a new legal problem confronting penal surgeons. A local sheriff was very reluctant to do his job. The Norfolk Annals for 1811 explained why:

\section{September 1811}

Mr Francis Morse and Mr Thomas Troughton were sworn into the office as Sheriffs of Norwich. Mr Morse appeared in his shooting dress, namely a short coat, leather breeches and so on; the steward preceding, as usual, to invest him with the gold chain, he refused to put on what he termed a 'bauble', nor would he wear the gown, he said, unless it was absolutely necessary. Mr Steward Alderson observed that his refusal seemed to convey disrespect to the court. Mr Morse disavowed any individual disrespect and said he would perform his office irrespective of outward forms. It was forced upon him in the expectation of obtaining a fine of $£ 80$, as he was convinced there was not a Gentleman on the Bench who believed when the precept was sent to him that he would serve the Office. ${ }^{79}$

Morse was a colourful and controversial local character. He had already fought a duel on 3 September 1797 in Norwich over an election skirmish. Of independent-thinking, few expected a radical to want to condemn murderers to death at the gallows or to apply the capital code for lesser property offences. Morse (like many of the surgeons that should have served as Master of Anatomy at London's Surgeon's Hall) had been expected to pay a fine to avoid the duty of leaving business ties to attend to his civic duty as Sheriff. He had though taken umbrage at the high financial penalty and turned up to be inaugurated at Norwich to make a public statement about the absurdity of the elaborate ceremonial trappings. It is informative that although his political objection was about expense and he declared a strong disliking for the Bloody Code nevertheless once a felon was condemned for murder he swore an oath to do his civic duty. He did not shirk from the unsavoury however objectionable the ceremonial trappings. For as The Norfolk Annals explained people in Norwich were very used to seeing dead things in country life and they had a hardened attitude when it came to the death penalty. Most residents were not squeamish about death, dying 
or criminal dissections. ${ }^{80}$ In the winter of 1811 at Xmas, for example, the Norwich Market was 'glutted' with dead birds from the annual pheasant shoots to be sold to London. There was by 22 December ' 800 hampers... having 10 stags' and altogether ' 720 horses' were needed to 'draw poultry, sausages and game sent within three days' of being killed in the fields of Norfolk 'from this city to the Metropolis'. ${ }^{81}$ Norwich folk employed in the game industry were not generally sentimental about the visceral nature of the dead in animal or human welfare. These local findings add provincial colour to a sea-change by the 1820 s in local hospital concerns about bad publicity surrounding human dissection. Criticisms had abated and been overtaken by a great deal of public interest in the medical death of the body, enthusiasm for the quasi-science of phrenology, and furthering medical education around Norwich. It was thus recorded that:

\section{August 1829}

At the Norwich Assizes, before Mr Justice Parkes, John Stratford (42) was found guilty of the murder of John Burgess, an inmate of Norwich Workhouse, by poisoning him with Arsenic on March 2nd. The execution took place on the roof of the new gaol on August 17th. After hanging the hour the body was removed to the lower court and conveyed to the lower court at the Guildhall where it was publically exposed for 2 hours. Thence it was conveyed to Norfolk and Norwich Hospital where Mazzotti, the modeller, took a cast of the head; and on the 18th Mr Crosse commenced a series on anatomical lectures at the dissection of the body. A public subscription was started for the family of the culprit ${ }^{82}$

Later we will return to the striking collection of criminal plaster-cast heads that have survived as material afterlives in regional museums. They attest to how by the 1820s expectations had changed at criminal dissections which had now become a different sort of performance of the teaching skills and research ambitions of penal surgeons in the dead-houses of provincial voluntary hospitals. Rather than trying to avoid such a duty it became de rigueur.

Touring a number of eighteenth-century provincial dissection venues in the archives, it becomes evident that criminal corpses were complicated medical research commodities. They were objectified in terms of curiosity and curated artefacts. After the Murder Act a new pathology of medical death required an accumulated anatomical knowledge and this became a competitive endeavour. Once medicine expanded her research horizons into sub-disciplines anatomists resented being stigmatized as instruments 
of legal redress. Rising consumer demand afforded different types of scientific opportunities with considerable business potential, but to realize these necessitated working on resurrected, as well as criminal dissections. From what was available at the gallows, given that the murder rate could not meet anatomical demand, provincial anatomists started to set their own research agendas. Many skilled practitioners came to the realization that a body of history was not simply in their collective keeping but in their individual making too. There was though an inherent contradiction in this research output. Defining the humanity of some depended on discovering the less than humane in others. Murderers destabilized what it meant to be a decent human being. Yet, their anatomical profiles had some features that were common to everyone when exposed to public view. For these complex reasons, the actions of the crowd at post-execution rites became a reflection of accepted modes of curiosity on which original research depended. Another example stands in for many in counties to the East of England, representative of what happened also in provincial areas bordering Suffolk, Essex, and Kent.

Lloyds Evening Post on 26 July 1769 reported that Benjamin Bush had been apprehended for assisting his lover in poisoning her husband, John Lott of Hythe in Kent. ${ }^{83}$ Standing trial Bush was found guilty and ordered to be executed at Penenden Heath in front of a crowd of five thousand people gathered at Maidstone. Before sentencing however Bush appealed to the judge not to dissect his body. In a petition to the judge the condemned stated that as he did not actually administer the poison he should not undergo post-mortem punishment. He claimed that he was not a vicious, violent murderer but an unfortunate foolish wretch in love. He knew that his body was prized as he was in his early twenties and would thus be dissected in full public view at Maidstone Shire Hall. Confronted however under cross-examination Bush conceded 'in an angry tone' that he was 'Guilty enough' of pre-meditated homicide. The judge was not inclined to show mercy. This backdrop sets in context why $\mathrm{Mr}$ John Chubbe, a penal surgeon from Ipswich made a special request to receive the criminal corpse.

John Chubbe (1741-1811) worked as both a physician and a surgeon at Ipswich. ${ }^{84} \mathrm{He}$ trained at Colchester in Essex, spent some time in London, and built a reputation for being a skilled dissector by the time of Benjamin Bush's criminal dissection in 1769. The Suffolk Garland highlighted that he was a remarkably forward-thinking doctor determined to do original anatomical research. ${ }^{85}$ Access to criminal dissections was essential if he was to prove that his theories had some basis in material reality. Between 
the 1760s and 1790s Chubbe had pursued three research foci: A Treatise on the Inflammation of the Breasts of Lying-in Women (London, 1779); articles published in the medical press on the use of digitalis for heart complaints and reviving patients that seemed dead' ${ }^{86}$; and a well-received book on improving sexual health called An Inquiry into the Nature of Venereal Disease and the remedy made use of to prevent its effects, principally with lotions, unguents, remedies and injections, particularly addressed to young men (London, 1782). He had also earned a reputation for skilled operations on the spleen with good survival rates. ${ }^{87}$ Tobias Smollett was praiseworthy in The Critical Review writing in 1783 that: 'Chubbe supports his opinions by plausible and ingenuous arguments' ${ }^{\prime 8}$ There was he commented a lot of theoretical opinions about how to 'treat violent gonorrhoea' but Chubbe's originality derived from his anatomical expertise whereby he 'enters into a physiological discussion on the nature of the venereal poison, the structure of the penis, the manner in which it is received, with its progress, and mode of action'. Of course to be convincing Chubbe needed to be well-networked with medico-legal officials from the 1760s when he started to practice surgery. This meant that when criminal corpses like that of Benjamin Bush became available he had a good chance of obtaining the body officially; provided that is medical death had already been established in the vicinity of an execution. The body could then be moved by fast coach across county boundaries. Behind Benjamin Bush's anti-dissection plea was a very real sense that his anatomy would be studied in-depth and dissected extensively including his sexual organs because he was a valuable opportunity cost in a busy medical market.

It was important in many provincial areas for penal surgeons to work together to acquire and redistribute bodies between each other to enhance their credibility through original research. Word of mouth was an important mode of communication in county life. In areas where fewer bodies tended to become available it was vital to get this right. This set of motivations is apparent for instance in the Transactions Book of the Huntingdon Medical and Surgical Society, 1792-1801 which contains medical cases and dissections of its founding members. Listed in its first printed rules of 1792 are the surgeons 'Samuel Allvey, Francis Hopkinson, John Smith, Joseph Vise, James Smyth, Joseph Michael, Richard Steward, Henry Oliver, Joseph Westbrook' (see Illustration 6.1, page 257). ${ }^{89}$ It is noteworthy that rule number VII states that they have all agreed to work together in 'Lincoln, Huntingdon and Rutland, or the City of Peterborough' to petition the local legal authorities in charge of executions to make sure their 
surgical society got first call on whatever criminal corpses became available at the gallows. They agreed to meet every six months at 'Peterborough, Bourne, Stamford, and Stilton' where each, with the exception of Allvery from St. Neots, had a private practice. Their close co-operation would eventually result in the formation of the Eastern Provincial Medical and Surgical Society 'uniting the practitioners of Cambridge, Essex, Huntingdon, Lincoln, Norfolk, Suffolk and other eastern counties' by $1836 . .^{90}$ By then, 'some 70 surgeons' had turned up to attend the opening meeting at Ipswich, providing evidence of how the criminal corpse in this wide expanse of the country was a catalyst for future professional ambitions.

Issues of age, gender, and the general condition of the body also impacted on the supply networks that developed between medical men. Yet, those practising surgery in East Anglia, and elsewhere, were all too aware that they had to take what they could get. Ethnicity for instance often determined the opportunity costs of research. In December 1771 it was thus reported in the London newspapers that:

The Curiosity and Impatience of the People to see the dead bodies of the Jews exposed at Surgeon's Hall in Tuesday was so Great that it was with utmost Difficulty that the Gentlemen of the Faculty [surgeons and their pupils] could gain Admittance...The Professor of Anatomy and $\mathrm{Mr}$ Bromfield were obliged to climb in at the Window, to the no small Diversion of the Crowd, which at last became so Great that it was impossible to open the gates to any of the Sheriffs... ${ }^{91}$

Meanwhile, 'Two Eminent Teeth-Drawers of this Town led a scramble for the teeth of the four Jews'. ${ }^{92}$ One of the gentleman managed to extract them first but not before the bereaved wife of one of the condemned begged to bury his body before dissection. He had been a doctor and she hoped that the surgeons would have some sympathy for her grieving plight. The widow was rejected on the grounds that the skeletons were needed for original research (Jews seldom being dissected since it was so offensive to their religious rites). It was explained to the relatives that as the crowd were determined to witness justice being done, it would have been foolhardy for the medico-legal officials to stop proceedings. Yet despite the obvious commotion and popular thirst for the spectacle once the standard cuts were made and the teeth stolen, the mob left the building. That so many ordinary spectators turned away from dissection to its extremities was again telling. None of the medical men present asked them to leave, nor on this occasion did the sheriff's men want to trigger a riot by acting with force. The crowd were in control of their curios- 
- At a Meeting of ajmedical and Surgrear sociéty cltablifheed in the Country in the year ${ }^{1} 79^{2}$, it was Refolyed that as the Intention of this Society is to improve its Members in the Practice of Medicine and Surgery, by receiving and communicating Medical' and Surgical Information, the following

Laws and Regulations be adopted.

\section{I.}

TPHAT each Member of this Society fhall pledge himfelf to affift every other1 Member of the fame, upon all Occafions, and in all Cafes of Surgical Operations; or any other Cafe of Surgery, in which the Safety of a Patient may be affected, or the Character of any individual Member concerned by the mifreprefentation of circum-
ftances, without Fee or Reward.

TH A This Society meet twice in cating the different Medical and Sur the Year for the exprefs Purpole of communiand to arrange fuch as may, be worthy of Publication have occurred in their practice;

THAT a t. III.

poled by a Member at one of the Half-yearly Meet of this Society, muft be pro. produce a Thefis, written by which Thefis fhall be immediately andidate, upon fome Medical or Surgical Subject. at the next Half-yearly Meeting, when one diffenting voice fhall exclude him.

THar Peterborough, Bourn, Stamf ord and Stilion, be the

yearly meetines, that each Place be taken in Rotation, places for holding HalfMembers prefert at the preceding Meeting.

THAT if any Accident happens to a

from attending the Duties of his Profeft Member of this Society, fo as to prevent him affift him as far as they are able.

$$
\text { VI. }
$$

THAT in cafe a Patient is in Circumftances to pay a confulting Surgeon, and re. quefts one to be called in on his own account, then each Member pledges himfelf
to call in one of this Society.

VII.

THAT, as the advantages to be derived from the examination of Bodies after Death muft be acknowledged by all, fo the difficulty of procuring Subiects inter Country muft be equally confelfed, therefore in the Cafe of the condects in the any Criminal with orders for Diffection, either in the Counties of Lineoln, Rutland or the City of Peterborough, a petition be prefented to the Sheriff or Mgdon, trates in the name of the Society for the Body by fome one of its Member Magif: a concife hiftory of the plan of the eftablifhment and the advantage which giving tainly accrue from the being fupplied with the Bodies of Criminals for Diffeatill cerVIII. THAT a Book be procured at the joint expence of the Society for the Purpofe of
inferting Cafes, Medical information, the Minutes of each meeting, \&c. IX.

TH AT a Secretary be appointed annually at whofe Houfe the Book fhall be Tept to infert fuch Medical Information, as he may have received through the Channel
of his Medical Correfpondents.

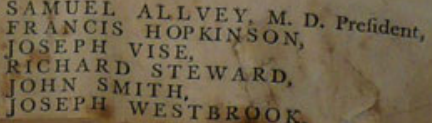

Illustration 6.1 (C) Huntingdon Record Office, Accession, 4715, Image taken 2013 by author of the 'Huntingdon Medical and Surgical Society, Transaction Book, 1792-1801'; Creative Commons Attribution-NonCommercial-ShareAlike 4.0 International License (CC BY-NC-SA 4.0) 
ity, and they exited when the 'perils of curiosity' became too much. An excess of accessibility, the unpalatable side of human nature, informed the actions of the crowd and their natural impulses. To be enlightened might have been a powerful inducement to participate in the deterrence value of post-execution 'harm' but it remained nauseating too. According to the Busy Body of 1759 this material fact explains why it was that the material afterlives of criminals were so engrossing for the post-execution crowd. Those that could not face dissection were still curious about the criminal destroyed. They thus relied on a material culture to satisfy their inquisitiveness (Illustration 6.1).

The Busy Body reporter also elaborated how: 'the ornaments in the Old Bailey and the School of Anatomy at Oxford are the only objects which enable us to form any idea about their [original criminal] appearance'. ${ }^{3}$ For many present the corpse became something 'other' and creating a material artefact made it somehow 'alive' in the popular imagination. Regardless of the unspoken reasons behind the timing of the crowd's departure from the dissection of the four Jewish criminals, the balance of evidence suggests that medicine did not simply distance itself from the mob to enhance professional-standing. Something much more complex happened because curiosity carried with it a complex array of emotional reactions and those present were seldom passive. Acquiring knife dexterity; cutting cleanly, working to the body-clock; putting in a good performance; being timely; co-ordinating with crowds of potential patients; appreciating that the social composition of audiences changed during a full-scale criminal dissection: these were all part of the choreography of punishment rites. Most contemporaries knew that it was what happened before the body was cut to its extremities that preserved in skeleton bone, tanned-skin, and plaster-cast material afterlives still identifiable in death. Otherwise most human remains simply disappeared down the drain, as criminal flesh disintegrated into dusty sweepings. There was then throughout our entire chronological focus a curious sense of respect for the dead, even for those that had led dissolute lives, and this came to be refabricated in museum settings too.

\section{Remaining Human: FaCing a Material REALITY}

At Worcester Royal Infirmary, ten plaster casts taken from criminal dissections were found in the 1930s (Illustration 6.2)..${ }^{94}$ This rogue's gallery makes a powerful statement about belonging and identity for those subject to the medical gaze of the Murder Act. Recently art historians, anthropologists, and archaeologists working in tandem have sought to inves- 


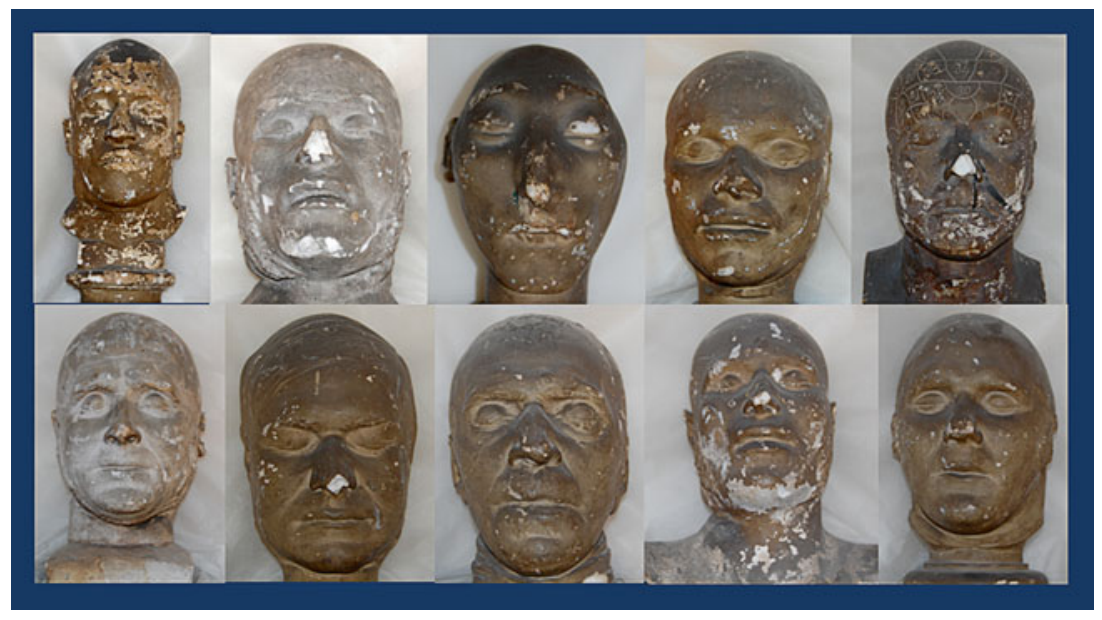

Illustration 6.2 (C) Charles Hastings Education Centre, Worcester, registered charity in England and Wales number 1074732 whose registered office is c/o John Yelland and Company, 22 Sansome Walk, Worcester, WRI ILS. In conjunction with the George Marshall Medical Museum, Worcester, criminal death masks rediscovered at Worcester Royal Infirmary in the 1930s. Reproduced here by kind permission of the Trustees under Creative Commons Attribution-NonCommercialShareAlike 4.0 International License (CC BY-NC-SA 4.0). See, also http://www. medicalmuseum.org.uk/story/DeathMasksnew.htm

tigate a 'bodily hierarchy' that these heads of criminals and other social outcasts symbolise in a post-modern museum culture. Across Europe, there has been a renewed interest on the 'basis of beliefs, mythologies and traditions about 'a cultural anatomy of the head'.$^{95}$ A 'headless tradition' still needs to be brought out of cold-storage to better inform criminal histories for it is apparent that 'headless dissection' was 'saying something different and distinctive from the skull' about the remaining humanity of the condemned. Being decapitated 'exploited the historicity of death' and its momento mori traditions by 'scrutinising mortality'. At the same time, at criminal dissections something very literal had to be faced as the head was separated from the torso. Plaster-casts embodied a re-assembling of the criminal-self to refabricate its human identity. There were three abstract things happening in the room when the head cast was taken of a condemned murderer. 
Death masks of all descriptions generated from criminal dissections reflected a widespread belief that the head and heart battled each other for supremacy of the early modern mind. ${ }^{96}$ At a time when explanations about medical death changed from heart-lung to brain-death taking a head cast was about the implied failure of personal moral responsibility and religious restraint. There was a very tangible medical sense that material afterlives came to represent a malfunction of a political economy that was losing its moral counterpart. Simultaneously there 'was a growing fascination with bodily fragments' and 'decapitation practices' within an 'increasingly strict judicial system'. ${ }^{97}$ These cultural trends arose out of Enlightenment sensibilities about whether the head should, or indeed could, rule the heart. Plaster-casts tended therefore to be seen as tokens of punishment with an implicit moral message that when the heart ruled the head dangerous criminality was mindless. Aesthetically modellers had therefore to make a crucial decision about how much of the corpse to feature in a new plastercast. What became known as 'collar heads' tended to feature the cranium and shoulders of the condemned; any deep rope marks on the neck were also replicated. Prominent features like a large nose or Adam's apple were usually pressed into the plaster of paris and sometimes wax, since these were clear marks of a dissolute criminal life too. In condemned females, the modeller thumbed into the closed eye-lids, emphasising the visible art-form of lid-watching (see, Chapter 2). These reflected contemporary superstitions about sunken eye-lids being seen as a sign of moral ruin; the eyes being the window of the soul. They depicted in capital-death how the corrupt body-shell had failed to contain the human-spirit needing to return to God to seek redemption for awful misdeeds. Masks were thus seen as prototypes of a corrupt self-portraiture. These the legal process had exposed to moral redress in transformative material mediums. Above all, they exuded 'purity, danger and gender' ${ }^{98}$ And all of this complexity, containing implicit and explicit moral scruples, was reflective of the shared emotional codes and values of an early modern mind-set that came to dissections curious about each criminal's headless afterlife.

The Liverpool Mercury on 21 January 1825 was one of many local newspapers to report how the 'new science... of phrenology' was doing its rounds in provincial life and had been the cause of much debate given that dissection seemed to be necessary to know the true anatomy of the criminal brain. Those that practised phrenology were said to take care not to stray from 'the plain path of evidence'. It was a discipline that some claimed combined 'the feelings, dispositions and talents of our particular nature, in 
the endless and inconceivable diversity in which it appears in human society'. Its advantage was that it reconciled 'the Creator' (old anatomy) with the 'material nature of dissection' (new anatomy) by showing:

That the mind is endowed with a plurality of innate faculties - Secondly, that each of these manifests itself through the medium of an appropriate organ, of which the brain is a congeries [conduit] - Thirdly, that the powers of manifesting each faculty bears a constant and uniform relation, ceteris paribus, to the size of the organ, or part of the brain, with which it is connected - Lastly, that it is possible to ascertain the relative size of the organ during life, by observing the different forms of the skull to which the brain gives shape. ${ }^{99}$

The argument ran that inside the headless was a mind-map of criminality if someone was trained to read it properly. These 'expert' views were naturally debated and disputed. The Royal Institute of Cornwall twelve months before the Liverpool meeting on 23 January 1824 invited Dr Percival Potts to speak. He travelled down to Truro by the post-chaise with his plaster casts taken from dissections of murderers done at St. Bartholomew's Hospital in London. Potts opened by saying that 'the novelty' of phrenology' was 'inviting, but its fundamental data was incapable of proof'; yet, it had captured the general public's imagination. He was sceptical about this but did express the view that based on his criminal dissection work he could not deny that:

It does appear that those who have allowed the impulse of the animal propensities and desires, to the commission of crime, have been mostly found to have thick heads and small cerebrums...I have examined that of a murderer in many respects... and found grounds for the opinion I have formed. ${ }^{100}$

At Norwich meanwhile, where there had been a great deal of dispute as to whether criminal dissections should be permitted to take place in the hospital dead-house, by the 1820s the staff had started to accumulate an extensive collection of material afterlives. This included the collar-head of John Stratford executed in 1829 (refer Section 1) sent to the Norfolk and Norwich Hospital Museum where it remains carefully catalogued today. ${ }^{101}$ It sits alongside:

Entry 637 - Normal Anatomy Number 2: Skeleton of Mr [John] Pycraft who was executed for murder [August 1820], Mr Langstaff dissected 
Entry 638 - Normal Anatomy Number 3: Skeleton of Mr Johnson who was executed for the murder of Mr Barker of Wells, Mr Langstaff dissected

Entry 1095 - Plaster Cast No. 135, Bust of Shalford executed for murder, Norfolk and Norwich Hospital dissection

Entry 1105 - Plaster Cast 145, Bust of Greenacre who was hanged for murder, Norfolk and Norwich Hospital dissection

Entry 1138 - Plaster Cast 178, Head of J B Rush - executed for the murder of Mr Jermsy [sic] and son of Stanfield Hall. Purchased. ${ }^{102}$

The longevity of these artefacts sets in context why when a renowned physician presented the Academy of Sciences in Paris with a 'piece of artificial anatomy, representing the body of a man according to its natural dimensions' and featuring 'the taking to pieces and putting together again all the various pieces of mechanism in their very fullest details', there was considerable interest in how 'the cranium may be opened and the brain taken out' ${ }^{103}$ The price was ' 3000 francs' and 'Mr M Ouroux' the inventor of a more interactive anatomical model to replace hand-held books generated considerable publicity in the London press.

In the English dispensary system meantime there was a great deal of interest in using new products other than wax to take casts of criminal heads. So much so that the Society of the Arts of London by 1841 had decided to award its gold medical to 'Mr Simpson...Surgeon to the Westminster General Dispensary' for the 'application of paper máché to the making of anatomical figures and models of morbid anatomy'. ${ }^{104}$ In an eulogy at the medal ceremony the orator of the Society recalled that Simpson 'some years ago turned his attention to the difficulty and expense of constructing' reproductions 'in consequence of the difficulty and expense at the time on procuring subjects for dissection'. A praiseworthy newspaper article announcing the prize explained that: 'The materials in use for anatomical models were wax and plaster, of which the former was found to be too expensive to come within the means of lecturers and students in general and was too delicate to be handled in the lecture room without the chance of considerable damage'. The problem with Plaster of Paris casts was that they were 'objectionable too on account of their great weight and brittleness'. Simpson thus perfected using paper máché 'worked into moulds taken from dissections' and these had an 'extreme lightness' when handled and were not easily damaged. They could be 'painted in oil coloured' to represent dissected parts and these were removable revealing the internal 
structures of notably the brain, heart and lungs. The method soon proved to be a best-seller. Simpson traded on the publicity of his gold medal to promote the 'extreme cheapness' of his paper máché design. He sold the collar-heads to the Royal Navy and East India Company keen to buy an alternative to wax that often softened in the hotter climate of the Far East. Material afterlives at home and far afield were about refabricating the criminal as public property. They were also about reproducing different price points - cheap paper máché, more expensive Plaster of Paris and costly wax models - all from the opportunity costs presented to penal surgeons. We end this heady tour therefore with a personal history that brings the physical journey of those that became objects of curiosity in a material culture, full circle.

Dr Thomas Kirkland (1721-98) surgeon of Ashby-de-la-Zouche personifies many of the complexities, contradictions and speculations that criminal dissections afforded from 1760 once the medico-legal choreography of the Murder Act was established in provincial England. He has featured periodically in this book receiving condemned bodies for postmortem punishment from Leicester gallows in Chapter 2 and then in Chapter 3 he gave critical medical evidence against Earl Ferrers whose method of criminal dissection set new standards on how to cut open the condemned body that became accepted practice in Chapter 4. Kirkland was at his most active between 1760 and 1790 at a critical time in the development of anatomy when its central purpose was reinvented. At first Kirkland did coroner's work before altering his methods from autopsy to anatomization and thence dissection after he became a penal surgeon. From this, he did original research on an eclectic and impressive range of conditions that reflected his patient caseload including: inter-cranial pressure arising from a head injury...industrial diseases...lumber abscess... scrofula...fractures...child-birth and puerperal fever'. ${ }^{105}$ Thus the Medical and Philosophical Commentaries by 1792 announced that Kirkland was recommending 'the utility of Opium in certain species of Apoplexy and Palsy [stroke complaints from brain maladies]. ${ }^{106}$ If criticised for doing original dissection work on the brain, Kirkland always defended that: ' $a$ peck of practice was worth a bushel of theory'. ${ }^{107}$ He likewise promoted the value of a private medical museum that became renowned in the Midlands. ${ }^{108}$

On Monday 30 August 1824 there was great excitement in Ashby-dela-Zouche because the Kirkland family had decided the sell their famous medical collection accumulated under the Murder Act. Over four auction days 'upwards of 300 volumes of medical and surgical books in lots' were 
viewed, and then purchased for ' $£ 3617 \mathrm{~s} 6 \mathrm{~d}$ ' in 16 lots by the end of day two'. This left the contents of the museum to be sold on day four, 4th September. People came from far and wide across the Midlands to buy the eclectic items. Their so-called provenance was attached to some sensational eighteenth-century crimes, as well as the punishment rites exacted on condemned criminals:

\section{Item Number in Sale Catalogue}

5: Key of Newgate at time Auction Prices of the Rebellion

8: Sir Edward Verrey's Skull, Slain at Edgehill

9: Part of an Egyptian Mummy

29: Stuffed Birds, Beasts and Reptiles in glass cases

30: Dresses and Shoes worn by several Dwarfs

37: Curious articles-includes

Dick Turpin's rope

6s $\quad 6 d$

$9 \mathrm{~s} \quad 0 \mathrm{~d}$

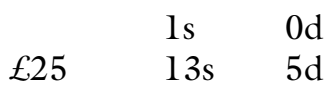

$7 s \quad 6 d$

$£ 1 \quad 0$ s $\quad 0 d$

Other curious items such as Earl Ferrers' rope, the Gunshot ball that shot his steward, skeletons from Criminal dissections and the entire Produce of the Museum

$\begin{array}{llll}\text { The auctioneer lists-Produce of Museum } & £ 75 & 2 s & 7 d\end{array}$ Expenses for the Sale Staff $\quad\left(\begin{array}{lll}£ 10 & 8 \mathrm{~s} & 7 \mathrm{~d})\end{array}\right.$

Total

First Day

2nd Day

3rd Day

4th Day

Total expenses

Total Profit from entire Sale

$£ 64 \quad 14 \quad 0 d$

$£ 198 \quad 0 \mathrm{~s} \quad 6 \mathrm{~d}$

$£ 36 \quad 17 \mathrm{~s} \quad 8 \mathrm{~d}$

$£ 31 \quad 5 \mathrm{~s} \quad 7 \mathrm{~d}$

$£ 75 \quad 2$ s $\quad 3 \mathrm{~d}$

$(£ 98 \quad 8 \mathrm{~s} \quad 5 \mathrm{~d})$

$£ 242 \quad 17$ s $\quad 7 d^{109}$

In Chapter 2 we encountered the skeleton of Timothy Dunn sent for cleaning in January 1796. At the time of the medical museum sale it could not be located. It was to have featured as a star-item at the auction but it had taken on a material afterlife of its own. Kirkland had paid for the 
skeleton to 'be boiled down'. It was then sent back to be viewed by local people at the White Horse public house in the town where Kirkland had exposed the condemned body. Thence it was 'used for the furtherance of medical knowledge, passed from one doctor to another' in the Midlands. Having gone on its medical travels it eventually went missing in the $1820 \mathrm{~s}$ when criminal dissections moved to purpose-built infirmaries in central England. Eventually it 'was found in a cupboard at 14 South Street Ashbyde-la-Zouche in 1930', but, by then, it was regarded with opprobrium and 'subsequently thrown down a well' in the town where by all accounts it disappeared from public view. As for the contents of the Kirkland medical museum that once occupied 63 Market street in Ashy-de-la-Zouche (the building was demolished in 1868), head-strung criminals were distributed far and wide, to be sold and resold, collected and dispersed over the next three generations. Even then, what remained became folklore. The 'public curiosity' that started with a crowded dramatic performance was refashioned into the tale of Thomas Kirkland that once did unsavoury criminal work and was Earl Ferrers' fatal undoing. The 'dead-end' of curiosity was seldom the end of the storyline.

\section{CONCLUSION}

The subject of the body divided is a familiar one in modern biomedicine. ${ }^{110}$ Yet it was the afterlives of criminal dissections created by the capital code that were the start of this powerful narrative in a history of punishment. Those in the crowd absorbed material realities because they had ample opportunities to be confronted by the headless, gutless, and faceless creatures of a 'new anatomy'. By the end of dissection, when arteries were typically empty of blood (because blood pools in the veins after death) ordinary people could speak in some sense about the curious things happening. That discourse had a transitional language because cutting the corpse was about debasement of the condemned torso, defacement of the visage including the eyes once seen as the window of the soul, and defilement of the heart and mind. In other words, all the traditional seats of humanity and spirituality that 'old anatomy' had once served in a scheme of divine creation were being turned upside down by different sorts of emotional conversations in the name of crime, justice and science under the Murder Act. Predictably perhaps being involved with criminal dissections created the narrative subtext for disconcerting discussions about the familiar, but abnormal. In a strong oral culture these involved talking emotionally in 
some capacity about 'normal curiosity', 'public curiosity', and 'morbid curiosity'; so much so, that the 'perils of curiosity' expressed a heightened sensitivity. There was more body-awareness, and the great irony was that it took the morally deviant to trigger this level of emotives: a self-contradictory paradox perhaps during the Enlightenment project that promoted reason and rationality as its central raison d'étre. There was the option of remaining silent but it is hardly credible to claim that all those that beat down the door to get inside a dissection venue staged their collective protest without emoting a single huff, puff, grunt, or word. It was likewise possible to be impervious but not likely given the synaesthesia stimulated in everyone. Accepting then that pushing and pulling to be on the inside gave voice to the archaeology of emotions considered normal at the time, makes it very necessary to revise an historical sense of the internal dynamics of the early modern crowd. ${ }^{11}$ Post-execution the potential existed for emotional expressions to be self-exploring and self-altering, in ways that William Reddy has identified. ${ }^{112}$ Those attending criminal dissections did not simply describe events but retold punishment dramas with human sentiments that were all about the essential quality of the immersive theatrical experience. Emotionally-speaking there was little point in going to a punishment rite if it was boring, banal, or baffling: the majority were 'out of body experiences', not in a modern quasi-spiritual sense, but in early modern terms of the staging of a public phantasm of criminal fleshiness to be visually consumed, materially composted, and emotionally recycled.

Recurrently there was a medical gaze at criminal dissections, but it was a very variable viewpoint. Audience members were repopulated over three to four days, peopled by those that came and went, and returned to see the body being punished post-execution. Not only was there a material reality to be faced as the body disintegrated but by preserving criminal heads for study a macabre sort of self-hood was recreated too. ${ }^{113}$ This was not simply public engagement on the part of the anatomical fraternity but an act of co-creation in which the crowd accepted that what was being represented by anatomical modellers-whether in wax, Plaster of Paris or paper maiche in a collar head-was 'real', 'the dangerous dead' and 'somehow alive though silenced forever'. This contemporary discourse was influenced by the quasi-sciences of galvanism and phrenology when electric impulses and nervous energy from brain dissection filled the punishment venue. Moving lips twitching seemed to make the headless speak and this set of experiences was enhanced by a sense of curiosity arising out of secrecy. Whichever sort of material afterlife was 
refabricated its artefacts were intimately related to research speculations that criminal dissections made feasible. Some of the work was perfunctory, some intriguing, some thought-provoking; each commodity was part of a mosaic of medical speculation and professional development. Anatomy under the Murder Act often resembled a macabre showcase or public drama of the unsavoury, as it had been for centuries. Yet, it is important to keep in mind that it was something far more intangible and curious too by the 1790s. Developing from a shared understanding that medical death was indefinite and had infinite varieties, the crowd and everyone present experienced something that every human being has always shared, and will arguably always do so. The journey from life to afterlife for many ordinary people generally leaves behind an emotionallycharged anatomical legacy of sorts.

\section{Notes}

1. Anon. (1770) 'On the Dissection of a Body', The Universal Magazine (August issue), Vol. 46, 98-9.

2. See, Section 2, where this original phrase is elaborated later in the chapter.

3. I am grateful to Dr Heather Shore current Head of Anatomy at Leicester University Medical School for permitting me to interview her about best practice in dissection sessions with new medical students during the formative stages of writing this book. To maintain human dignity at all times, no more than one third of a donated body is dissected. There is then an annual service of commemoration and thanksgiving for the gift of each body to medical education.

4. Refer, E T Hurren (2011), Dying for Victorian Medicine: English Anatomy and its Trade in the Dead Poor c. 1832-1929, (Basingstoke: Palgrave Macmillan).

5. West Yorkshire Archive Service, Bradford Office, SpSt/11/5/1/2, William Hey Correspondence, Letter from Hey to William Stanhope, 21 May 1785.

6. 'Execution of Thomas for Murder', The Times, 31 August 1822, Issue 11339 , p. 2.

7. All original quotes appear in Ernest Reginald Frizelle (1988), The Life and Times of the Royal Infirmary at Leicester: The Making of a Teaching Hospital 1766-1800 (Leicester: Leicester Medical Society), chapter XXI, pp. 275-6. The book is based on primary sources located at Leicester Record Office [hereafter LRO], Leicester Infirmary Minute Books [hereafter LIMB], 17 December, \& 29 December 1807, 8 June 1819, and 19 December 1822. 
8. Frizelle, Royal Infirmary, p. 265, and discussed in LRO, LIMB, 20 August 1816, 8 April 1817, 3 August 1817, and 10 August 1817.

9. This sets in context why LRO, LIMB, 23 March 1822 states that: 'It being resolved unanimously that the practice of exhibiting the bodies of the unfortunate persons given to the Infirmary for dissection appeared to us improper and, that in future, no such exhibition is permitted'. The dissection room door was being closed in principle, though not necessarily in practice, as we shall see later.

10. On fatal medical accidents in the Darwin family history, see, 'On the Life and Writings of Erasmus Darwin' (1822), The London Magazine, (December issue), 520-9, medical death by dissection at p. 522 .

11. Editorial feature (1788), 'The Life of Charles Darwin 1758-1778', Medical and Philosophical Commentaries, Vol. 5, 329-36.

12. Thomas Alcock (1827), An Essay in the Use of Chlorurets of Oxide of Sodium and Lime as Powerful Disinfecting Agents and of the Chloruret of Oxide of Sodium more especially as a Remedy of Considerable Efficacy in the Treatment of Gangrene, Phagedenic, Syphilitic, and Ill-Conditioned Ulcers, Mortifications and Various Other Diseases dedicated to the Right Hon. Robert Peel (Derby and London: Burgess and Hill), p. 14.

13. Ibid., p. 15.

14. See, Alcock, Use of Chlorurets, section 'On the Prevention of Putrefaction in conducted private Anatomical Studies', pp. 16-20.

15. See, Elizabeth Barry (2008), 'From epitaph to obituary: death and celebrity in eighteenth-century culture', International Journal of Cultural Studies, Vol. 11 (No. 3), 259-75, in which she argues that many of the attributes of modern fame can be identified as starting in the eighteenthcentury when death became 'news' and capital punishment captured the headlines. Yet, the physical obituary of a criminal dissection happening before the crowd and its medical epitaph is seldom studied as an intrinsic aspect of the eighteenth-century fame culture.

16. See, Alcock, Use of Chlorurets, p. 21.

17. Ibid., pp. 21-2.

18. See, Alcock, Use of Chlorurets, p. 11.

19. Refer, 'Execution of A. and M. McKeand for the Murder at Winton', The Observer, 27 August 1826, pp. 4-5.

20. Refer, 'Execution of the Keands', The Manchester Guardian, 26 August 1826, pp. 1-2, quote at p. 2.

21. On his career, see, The National Archives [hereafter TNA], BPP, (1812-3), $\mathrm{V}$, Report of the Commissioners on the State Lancaster Prison and the Treatment of Prisoners Therein, p. 34, and later printed as State of Lancaster Gaol (1812) (London: Lords and Commons Reports), entry 3 July 1812, pp. 897-8. 
22. See, for instance, William M. Reddy (2001) The Navigation of Feeling: $A$ Framework for the History of Emotions, (Cambridge: Cambridge University Press), p. 96.

23. 'Murder at Winton: Execution of the Keands', The Age, 26 August 1826, p. 542 , Issue, 68 .

24. Nottingham County Record Office, BB34.8, 'Gallows Rememberancer for 1779', pp. 47-8.

25. Neil Kenny (2004), The Uses of Curiosity in Early Modern France and Germany, (Oxford: Oxford University Press), especially pages 1-4, long quote at p. 1.

26. Ibid., p. 2.

27. Kenny, Uses of Curiosity, p. 4.

28. Ibid., p. 13.

29. Kenny, Uses of Curiosity, p. 159.

30. See, E. T. Hurren (27 July 2013), 'The Dangerous Dead: Dissecting the Criminal Corpse', Lancet, Vol. 382, Issue No. 9889, pp. pp. 302-3, on the dissections of William Hey at Leeds.

31. Reconstructed from, Leeds University Special Collections. MS 504/1/3, Manuscript of Mr William Hey, Senior Surgeon to the Leeds General Infirmary.

32. See also S. T. Anning and W. K. J. Walls (1982), A History of Leeds Medical School (Leeds: Leeds University Press).

33. Erasmus Darwin (1803), The Temple of Nature or The Origins of Life (London: Thomas Bensley Publishers), Cant. I. 1, 250, a poem published the year after his death.

34. Derbyshire General Infirmary was opened in October 1810 at a cost of $£ 30$, 000 raised by local subscriptions. It had two day rooms for convalescents, a fever house for infectious diseases, and could accommodate 80 patients on its main medical wards. They were attended by 'three physicians' (Bent, Fox junior and Baker), 'four surgeons' (Godwin, Wright, Douglas Fox, and another rotating surgeon) and a 'house apothecary' (Richard Dix), as well as Richard Forrester Forrester [sic] physician who acted as semi-retired 'consulting physician', see, Daniel and Samuel Lysons (1817), Magna Britannia: Volume 5: Derbyshire, (Derby: Walker and Co), pp. 94-129.

35. See, detailed letter on the dissection to the Editor of the Medical and Physical Journal, Volume 18, p. 157.

36. Darwin was enormously over-weight and probably suffered a stroke and collapsed lung caused by his obesity. At 24 stone, he usually sent ahead his assistant to check that when attending a private patient the wooden floor of their house could take his weight.

37. S. Glover and T Noble eds. (1829), A History of the County of Derby Volume II, (Derby: Henry Mozley and son) p. 593. 
38. William Hutton (1817), The History of Derby (London: Nicols and son and Bentley), p. 202, written in 1791 but published in 1817.

39. Francis Fox senior had in fact been a prominent physician in Derby and bequeathed his business dealings to Francis junior who appears to have been related to Douglas Fox the surgeon by marriage. See, TNA, PROB $/ 11 / 1212 / 32$, Will of Francis Fox, gentleman of Derby, 2 December 1791 .

40. Erasmus Darwin (1803), The Temple of Nature or The Origin of Society, "Additional Notes II, The Faculties of the Sensorium" to accompany the poem (London: Thomas Bensley Publishers).

41. Ibid., Additional Notes II, I-VI, explain how in the head there might remain 'a certain quantity of sensation' on the cusp of life-death in the brain's 'sensorium'.

42. Refer, C. U. M. Smith and Robert Arnott (2005), The Genius of Erasmus Darwin, (Farnham, Hampshire: Ashgate), on how Darwin's interest in resuscitation and galvanic experiments may have directly influenced Mary Shelley's Frankenstein (London, 1818).

43. See, endnote 34 above and Letters, 'To the Editors', The Medical and Physical Journal, Vol. 18, pp. 309-14.

44. Ibid.

45. Refer previous chapters and for a recent reappraisal, I am grateful to Shane McCorrsetine (2015) for sharing with me his new manuscript now published as, William Corder and the Red Barn Murder: Journeys of the Criminal Body (Basingstoke: Palgrave Pivot).

46. LRO, LIMB, LRO/13064/13, 23 June 1814-30 June 1819, entry dated 17 November 1815.

47. See, by way of example, Stanley Finger (2000), Minds Behind the Brain: A History of the Pioneers and their Discoveries (New York: Oxford University Press) and Carl Zimmer (2005), Soul Made Flesh: The Discovery of the Brain and How it Changed the World (New York: Simon and Schuster, Free Press).

48. LRO, LIMB, 23 March 1822.

49. As featured in, Frizelle, Royal Infirmary Leicester, p. 264.

50. 'Murder Near Manchester' The Age, 4 June 1826, p. 443, Issue 56.

51. Ibid.

52. 'Execution of the Keands', The Manchester Guardian, 26 August 1826, attached to which there was a sketch of the murderers being apprehended outside an Inn which warned readers not to believe that it was a good resemblance but was very defectively drawn.

53. See, Anon, (1819), A Full Account of the Most Horrid Murder Committed by Thomas Weems or Weyms a Miller, Upon the body of his Wife by Strangling 
Her with a Garter near Puckeridge Hertfordshire (London: Charles Piggot publisher of Clerkenwell).

54. 'Execution of Weems and Galvanic Experiments upon the Body', Letter To the Editor, Morning Chronicle, Saturday 14 August, 1819, column 2, 15691.

55. 'Execution of Weems', Cambridge Chronicle and Journal, 13 August 1819 issue, carried a full account of the experimental stages.

56. Ibid.

57. Okes was the gaol surgeon at Cambridge Castle on a salary of $£ 20$ in 1819. By 1833, he worked at the Old Addenbrooke's Hospital on Trumpington Street near the Anatomy Theatre where he delivered medical lectures on surgery to a new school of medicine founded on the hospital site. He was described as a 'surgeon of high character' (1815) in the Annals of Cambridge, (Cambridge: Warwick and Co), p. 525.

58. 'Execution of Weems and Galvanic Experiments upon the Body', Letter To the Editor, Morning Chronicle, Saturday 14 August, 1819, column 2, 15691.

59. Members of the Okes doctoring family around Cambridge were also intrigued by original research on nerve and spinal complaints, branching out to work on spina bifida in 1812. One wrote that he was 'opposed to puncture or pressure' of the malformed spine based on what he had seen from bodies in fatal trauma, see, 'Intelligence Spina Bifida' in (1812) The New England Journal of Medicine and Surgery and the Collateral Branches of Science conducted by a Number of Physicians, Volume 1, (Boston: Wait \& Co), pp. 98-102, q. at p. 101.

60. All the letters cited are part of a collection now retained at East Sussex Record Office [hereafter called ESRO], The Archive of the Frewen Collection, Family of Brickwall in Northiam [hereafter referred to as FC], more especially, ref. 2567-2658, Letters from Dr Thomas Bishopp of Leicester, c.1792-1811, and others cited per letter item.

61. ESRO, FC, FRE/2576, 7 October 1792, Thomas Bishopp to John Frewen.

62. ESRO, FC, FRE/2568, 29 November 1792, Thomas Bishopp to John Frewen.

63. ESRO, FC, FRE/2572 \& FRE/2575, 10 April 1794 \& 26 October 1794, Thomas Bishopp to John Frewen, reviews his dissection activities since 1792 and of late.

64. ESRO, FC, FRE/2572, 10 April 1794, Thomas Bishopp to John Frewen.

65. ESRO, FC, FRE2576, 7 November 1794, Thomas Bishopp to John Frewen. 
66. ESRO, FC, FRE/2598, 24 October 1797, dated by post mark, Thomas Bishopp to John Frewen. Dr Chessner according to other letters was often jealous of his pupils, whether this was hearsay or based on personal experience is not clear, but see, FRE/2578, 14 Jan 1796.

67. ESRO, FC, FRE/2586, 6 March 1797, Thomas Bishopp to John Frewen.

68. Edward Le Grand died suddenly at Canterbury in 1797. He was described in The Monthly Magazine or British Register Volume 3 for 1797 as 'a promising young man, whose endowments would have done honour to a riper age', but sadly no more, p. 169.

69. ESRO, FC, FRE/2658/97, no date, watermarked 1802, Thomas Bishopp to John Frewen.

70. ESRO, FC, FRE/2608, 2 June 1806, Thomas Bishopp to John Frewen.

71. ESRO, FC, FRE/2658/14, undated but likely to pre-date 1807, Thomas Bishopp to Frewen.

72. ESRO, FC, FRE/2603, 3 March 1804, Thomas Bishopp to John Frewen: the latter was taking the water cure at Bath staying at 7 South Parade and was very interested in medical fashions and the general business climate.

73. 'Middlesex Sessions', Morning Post, 15 September, 1819, Issue 15181, column 5.

74. 'Case of King versus Cundice (1822), Surrey Lent Assizes: Selling the body of a convict for dissection', The Observer, 8 April 1822.

75. Ibid.

76. See, endnote 73 above.

77. Norwich Record Office [hereafter NRO], NNH 1/6, Norwich and Norfolk Hospital Minutes 12 July 1794-13 July 1799, entry 12 August 1797.

78. NRO, NNH 1/6, Norwich and Norfolk Hospital Minute Books, 12 July 1794-13 July 1799, quoted entry 19 August 1797.

79. Charles Mackie (1901), Norfolk Annals (Norwich: Kessinger Publishing), entries 1811, p. 78.

80. Ibid., p. 74.

81. Mackie, Norfolk Annals, p. 79.

82. Ibid., p. 157.

83. Case reconstructed from Lloyds Evening Post, 28 July 1769 (a) and (b).

84. See, Lloyds Evening Post, 16 September 1769 (b).

85. James Ford (1801), The Suffolk Garland (Ipswich: John Row), pp. 180-1.

86. See for instance, The London Medical and Physical Journal (Volume 4), p. 137.

87. John Bensusan Butt edited by Shani D'Cruze (2009), Essex in the Age of Enlightenment : Essays in Historical Biography (Colchester: e-publisher lulu.com), p. 126. 
88. Tobias George Smollett (1793), 'Book Review', The Critical Review or Annals of Literature, Vol. 54, p. 155.

89. Huntingdon Record Office, Accession 4715, Huntingdon Medical and Surgical Society, Transactions Book 1792-1801, acquired 2000, accessed 2013.

90. Announcement (1836), 'Eastern Provincial Medical and Surgical Society', Medico-Chirurgical Review and Journal of Medical Science, Vol. 28 (January), p. 166.

91. Public Advertiser, 14 December 1771.

92. Teeth were often extracted and sold on by barber-surgeons who did criminal dissections especially in London and Newcastle. In the capital John Hunter (1778) The Natural History of Human Teeth I (with William Coombe), (London: J Johnson) stressed that good teeth were essential for healthy digestion. They soon became a valuable medical commodity, replacing bad teeth with a healthier set of criminal teeth. Newcastle barber surgeons concurred, selling criminal sets of teeth from their Surgeon's Hall and expanding dentistry in the vicinity by the 1770s. One Newcastle barber surgeon named Charles Edward Whitlock even ran a dentistry practice and a company of actors from the Hall to maximise business profits, see, John Boyes (1957), 'Medicine and Dentistry in Newcastle Upon Tyne in the Eighteenth-Century', Proceedings of the Royal Society of Medicine, Vol. 50 (April), 299-335.

93. Busy Body, 25 October, 1759.

94. Accessed at, http://www.medicalmuseum.org.uk/story/DeathMasksnew. htm.

95. Catrien Santing and Barbara Baert eds. (2013), Disembodied Heads in Medieval and Early Modern Culture (Oxfordshire: Brill Publications), p. 9.

96. A point well-made for instance in Ole M. Høystad (2007), A History of the Heart (London: Reaktion Books).

97. Santing and Baert, Disembodied Heads, p. 7.

98. Ibid., p. 12.

99. 'Phrenology lecture by Dr Cameron,' Liverpool Mercury, 21 January, 1825 , Issue 713 , column 3.

100. 'Royal Institution of Cornwall - Phrenology Speaker', Royal Cornwall Gazette, Falmouth Packet and Plymouth Journal, Truro, 3 January, 1824, Issue 1071, page 1 , column 1 .

101. Mackie, Norfolk Annals, entry 14 August 1829.

102. NRO, NNH 29/2, Catalogue of the Norfolk and Norwich Hospital Museum, where $\mathrm{N}$ indicates Normal Anatomy, $\mathrm{P}$ is a Plaster Cast.

103. 'Important Anatomical Invention', The Morning Chronicle, Saturday 2 April 1824, Issue 17460, page 1, column 1. 
104. 'Anatomical Models', 'Manchester Guardian, 26 May 1841, Issue 1841, p. 3, column 3 .

105. R T Austin (1986), 'Dr Thomas Kirkland of Ashby-de-la-Zouche: 1721-98', British Medical Journal, Vol. 293 (25th October), 1075-6.

106. Announcement of Dr Kirkland's latest original work in (1792) Medical and Philosophical Commentaries, Vol. 16, p. 396.

107. Cited in a review of the career of Mr William Chessher, a fellow surgeon, in (1832) The Annual Biography and Obituary for the Year of 1832, Vol. 16, (London: Longman), p. 401.

108. Refer, TNA, PROB 11/1310/135, Will of Thomas Kirkland, Doctor of Medicine, Doctor of Physic, Ashby-de-la-Zouche, 21 July 1798.

109. LRO, P222, Photocopy of Catalogue Number 2222-Copy of the Sale of $M r$ Thomas Kirkland's goods and Museum upon his death-sold on the premises by the family of Kirkland senior and junior-on the death of the latter in 1824. The profit was a decent 3-year living for the Kirkham family.

110. See, Sarah Ferber and Sally Wilde eds., (2011), The Body Divided: Human Beings and Human 'Material' in Modern Medical History (Farnham, Surrey: Ashgate).

111. Refer, Sarah Tarlow (2012), 'The Archaeology of Emotion and Effect', Annual Review of Anthropology, Vol. 41, 169-85.

112. Again, see, Reddy, The Navigation of Feeling \& his (2009),'Historical Research on the Self and Emotions', Emotion Review, I, 302-315.

113. A point made forcibly by Arjan R de Koomen 'The Self-Portrait 'En Décapité: Interpreting Artistic Self-Assertion' in Santing and Baert Disembodied Heads, chapter 7, pp. 191-222.

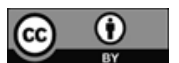

This chapter is distributed under the terms of the Creative Commons Attribution 4.0 International License (http://creativecommons.org/licenses/by/4.0/), which permits use, duplication, adaptation, distribution and reproduction in any medium or format, as long as you give appropriate credit to the original author(s) and the source, provide a link to the Creative Commons license and indicate if changes were made.

The images or other third party material in this book are included in the work's Creative Commons license, unless indicated otherwise in the credit line; if such material is not included in the work's Creative Commons license and the respective action is not permitted by statutory regulation, users will need to obtain permission from the license holder to duplicate, adapt or reproduce the material. 